\title{
Defective Endochondral Ossification-Derived Matrix and Bone Cells Alter the Lymphopoietic Niche in Collagen X Mouse Models
}

\author{
Elizabeth Sweeney, ${ }^{1}$ Douglas Roberts, ${ }^{1}$ Angela Lin, ${ }^{2}$ Robert Guldberg, ${ }^{2}$ and Olena Jacenko ${ }^{1}$
}

Despite the appreciated interdependence of skeletal and hematopoietic development, the cell and matrix components of the hematopoietic niche remain to be fully defined. Utilizing mice with disrupted function of collagen $\mathrm{X}(\mathrm{ColX})$, a major hypertrophic cartilage matrix protein associated with endochondral ossification, our data identified a cytokine defect in trabecular bone cells at the chondro-osseous hematopoietic niche as a cause for aberrant B lymphopoiesis in these mice. Specifically, analysis of ColX transgenic and null mouse chondroosseous regions via micro-computed tomography revealed an altered trabecular bone environment. Additionally, cocultures with hematopoietic and chondro-osseous cell types highlighted impaired hematopoietic support by ColX transgenic and null mouse derived trabecular bone cells. Further, cytokine arrays with conditioned media from the trabecular osteoblast cocultures suggested an aberrant hematopoietic cytokine milieu within the chondro-osseous niche of the ColX deficient mice. Accordingly, B lymphopoiesis was rescued in the ColX mouse derived trabecular osteoblast cocultures with interlukin-7, stem cell factor, and stromal derived factor-1 supplementation. Moreover, B cell development was restored in vivo after injections of interlukin-7. These data support our hypothesis that endrochondrally-derived trabecular bone cells and matrix constituents provide cytokine-rich niches for hematopoiesis. Furthermore, this study contributes to the emerging concept that niche defects may underlie certain immuno-osseous and hematopoietic disorders.

\section{Introduction}

A LTHOUGH THE INTERDEPENDENCE of the skeletal and hematopoietic systems during development, homeostasis, and aging has long been apparent [1-3], the cell types and extracellular matrix (ECM) components involved in establishing and maintaining hematopoietic niches are still being defined [49]. In vertebrates, the coordinate development of the skeletohematopoietic systems relies on endochondral ossification (EO). Through this process, a transient skeletal "blueprint" comprised of a hypertrophic cartilage matrix supports the formation of trabecular bone and a hematopoietic marrow [2,10]. With the onset of EO, the marrow becomes the primary site of hematopoiesis postparturition [1], and serves as a model for defining various hematopoietic niches, including the hematopoietic stem and progenitor cell and lymphopoietic niches.

Multiple recent studies have implicated osteoblasts [1123], perivascular mesenchymal cells [24-26] and stromal cells [27-32] as the cellular components of hematopoietic niches. Moreover, several hematopoietic cytokines, including interleukin (IL)-7 and stromal derived factor (SDF)-1 (or CXCL12), have been implicated in B lymphopoiesis [21,31,33,34].
We had hypothesized that hematopoietic niches arise through EO-derived cells and matrices, based on the unique skeleto-hematopoietic defects observed in the collagen $X$ (ColX) transgenic (Tg) and null (KO) mice. In these mice, the function of ColX, the major hypertrophic cartilage matrix protein, is impaired either by transgenesis leading to dominant interference at the protein level [35-37], or by gene inactivation [35,38-43]. We had reported that both the ColX-Tg and $\mathrm{KO}$ mice have similar structural changes at the chondroosseous junction (COJ), which represents the interface between the growth plate, trabecular bone, and the hematopoietic marrow. These alterations include the disruption of the hypertrophic chondrocyte pericelluar network, likely consisting of ColX, and decreased staining for heparan sulfate proteoglycans (HSPG) in hypertrophic cartilage and trabecular bone $[36,44]$. Further, all ColX-Tg/KO mice have diminished B lymphopoiesis throughout life, aberrant serum cytokines and impaired immune responses [38-40,42]. Our studies linked these hematopoietic defects directly to ColX disruption at the COJ, and thus, were the first to implicate hypertrophic cartilage and the COJ as contributors to the lymphopoietic niche $[39,43,45,46]$.

\footnotetext{
${ }^{1}$ Department of Animal Biology, School of Veterinary Medicine, University of Pennsylvania, Philadelphia, Pennsylvania.

${ }^{2}$ Wallace H. Coulter Department of Biomedical Engineering, Georgia Institute of Technology, Atlanta, Georgia.
} 
The purpose of this study was to identify which COJ cell type(s) from the ColX-Tg/KO mice were defective in hematopoietic support, and thus, were contributing to aberrant B lymphopoiesis. We first demonstrated an altered trabecular bone matrix within the COJ of the ColX-Tg/KO mice via micro-computed tomography (micro-CT). Next, through coculture assays, we identified the EO-derived trabecular bone cell cultures from the ColX-KO mice as defective in their ability to support lymphopoiesis. Further, we demonstrated reduced levels of B lymphopoietic cytokines, in particular IL7, stem cell factor (SCF), and SDF-1, in the supernatant of ColX-KO mouse trabecular bone cell cultures, as well as subtle differences in their localization and staining intensities within the COJ. In accord, B cell outgrowth was rescued in ColX-KO mouse trabecular bone cell cultures following cytokine supplementation. Moreover, in vivo injections of IL-7 to ColX-Tg/KO mice restored marrow B cell levels to that of wild type during the periods of both lymphocyte and skeletal development. Collectively, these data support our hypothesized model that the EO-derived COJ and associated ECM constituents provide cytokine rich niches for lymphopoiesis in the marrow.

\section{Materials and Methods}

\section{Mouse maintenance}

Animals were handled in accordance with good animal practice as defined by the University of Pennsylvania IACUC, and all animal work was approved by the Animal Welfare Committee. Colony maintenance and daily surveillance were previously described [40]. ColX mouse strains used in this

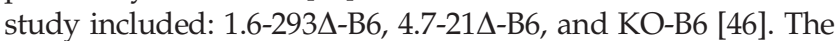
B6.SJL-Ptprc ${ }^{\mathrm{a}} \mathrm{Pepc}^{\mathrm{b}}$ mice were from Jackson Labs.

\section{Micro-CT assays}

Tibiae from day $21 \mathrm{WT}$ and ColX-Tg/KO mice $(n=3-4)$ were fixed ( $4 \%$ formaldehyde/phosphate-buffered saline; PBS, $\mathrm{pH} 7.4 ; 4^{\circ} \mathrm{C}$ ), and positioned vertically in a micro-CT specimen tube of $16 \mathrm{~mm}$ diameter. Volumes of interest in the mid-diaphysis $(1.6 \mathrm{~mm})$ and distal femur $(2.4 \mathrm{~mm})$ were scanned with a $\mu \mathrm{CT} 40$ (Scanco Medical) at $\mathrm{E}=55 \mathrm{kVp}$, $\mathrm{I}=145 \mu \mathrm{A}$, integration time $=200 \mathrm{~ms}$, voxel size $16 \mu \mathrm{m}$. Global thresholding values to segment bone from background were based on histogram analysis and visual inspection (Gauss sigma/support/threshold for mid-diaphysis $=0.8 / 1 / 150$, epiphysis $=0.5 / 1 / 130$, metaphyseal trabecular bone $=0.5 / 1 /$ 123, metaphyseal cortical bone $0.8 / 1 / 130$ ). These segmentation values were applied to generate $3 \mathrm{D}$ binarized images, which were used to quantify bone morphometry and density. Midshaft analyses were performed to determine cortical parameters for the mid-diaphysis (bone volume, cortical thickness, cross-sectional area, anisotropy, maximum moment of inertia, and mineral density). In the distal femur, trabecular bone in two regions on either side of the growth plate (epiphysis- $-0.32 \mathrm{~mm}$, metaphysis- $0.56 \mathrm{~mm}$ ) was assessed for bone volume, volume fraction, average trabecular thickness, spacing, number, connectivity, anisotropy, and mineral density. Morphometric parameters were computed using direct distance transformation [47]. Cortical bone in the metaphysis was assessed for bone volume, volume fraction, and mineral density.

\section{Proliferation assay}

Marrows were aspirated from both hind limbs of week-3 wild type, ColX-KO and ColX-Tg mice. Cells were counted and plated in $60 \mathrm{~mm}$ tissue culture dishes for growth in DMEM (Gibco) with 10\% FBS (Hyclone), penicillin/streptomycin (Gibco), $0.09 \mathrm{mM}$ L-ascorbic acid 2-phosphate sesquimagnesium salt hydrate (Sigma) at $37^{\circ} \mathrm{C}$. On days four and seven, the media were changed, and on days ten-tofourteen the cells were harvested with trypsin (Gibco). Cells were then replated at $2 \times 10^{4} \mathrm{c} / \mathrm{cm}^{2}$, in tissue culture 96 -well flat bottom plates in eight replicas per mouse. The protocol from the Roche WST-1 kit was followed and proliferation was measured from days three to eleven.

\section{Colony forming assays}

For colony-forming unit fibroblast alkaline phosphatase colonies (CFU-F/ALP), marrow from week-3 wild type, ColX-KO and ColX-Tg mice was aspirated from both hind limbs. Cells were counted and plated at $2 \times 10^{5} \mathrm{c} / \mathrm{cm}^{2}$ in $60 \mathrm{~mm}$ tissue culture dishes for growth in DMEM (Gibco) with 10\% FBS (Hyclone), penicillin/streptomycin (Gibco), $0.09 \mathrm{mM}$ L-ascorbic acid 2-phosphate sesquimagnesium salt hydrate (Sigma) at $37^{\circ} \mathrm{C}$. On day 4 , a half media change was performed. Full media changes were then made on days 7 and 10, with colony staining on day 14. ALP staining was done with the Sigma kit (86C) as per manufacturer's recommendations. Colonies with $\geq 20$ cells were counted manually.

For CFU preosteoblast colonies (CFU-O), marrow cells were harvested and grown as above; however, from day 7 on, the media used were DMEM, 10\% FBS, penicillin/ streptomycin, $0.3 \mathrm{mM}$ L-ascorbic acid (Sigma), $10 \mathrm{mM} \beta$ glycerol phosphate (Sigma), and $10^{-8} \mathrm{M}$ dexamethasone (Sigma). On day 21, colonies were stained with a $1 \%$ solution of Alizarin red S (Sigma) for $10 \mathrm{~min}$ at RT. Plates were washed $3 \times$ with water and colonies were documented on a dissecting scope with the Spot Flex digital camera, Spot software and brightness/contrast was adjusted with Adobe Photoshop CS. 5\% cetylpyridinium chloride in $10 \mathrm{mM}$ sodium phosphate dibasic heptahydrate $(\mathrm{pH} 7)$ was used to solubilize the Alizarin red S for $30 \mathrm{~min}$ at RT. Absorbance was measured at $562 \mathrm{~nm}$.

\section{Histology}

Tissues were fixed ( $4 \%$ formaldehyde/PBS, $\mathrm{pH} 7.4 ; 4^{\circ} \mathrm{C}$, $48 \mathrm{~h}$ ) and decalcified (4\% formalin, 1\% sodium acetate, $10 \%$ EDTA, RT; 4 h). Following a wash in deionized water, samples were dehydrated in ascending ethanols, cleared with Propar (Anatech), paraffin-embedded, and sections cut at $6 \mu \mathrm{m}$.

\section{Immunohistochemistry}

PBS rinsed cell cultures grown in chamber slides (Lab-Tek) were fixed (acetone:methanol 1:1; $1 \mathrm{~min}$ ) and washed with PBS. For collagen I staining, fibers were swelled $(0.1 \mathrm{~N}$ acetic acid, $30 \mathrm{~min}$ ), washed in PBS, and epitopes revealed with testicular hyaluronidase (Sigma; $1 \mathrm{mg} / \mathrm{mL}$ in $\mathrm{PBS}, 37^{\circ} \mathrm{C}$, $15 \mathrm{~min}$ ). Samples were washed (PBS) and blocked with FBS (Gibco; 4\% in PBS, RT, $30 \mathrm{~min}$ ). Primary antibodies, collagen 
I (Abcam; 1:100), collagen II (Thermo Scientific; 1:75), and ColX (gift from Dr. Chan, 1:3000) were incubated (RT, $60 \mathrm{~min}$ ) and then washed with block solution. Samples stained with Osteocalcin (ARP, 1:200) and Osteopontin (ARP; $1 \mu \mathrm{g} / \mathrm{mL}$ ) were fixed with formaldehyde $\left(4 \%, 4{ }^{\circ} \mathrm{C}\right.$, $20 \mathrm{~min}$ ) and permeabilized with triton X (Sigma; 0.1\% in PBS, $\left.4^{\circ} \mathrm{C}, 10 \mathrm{~min}\right)$. Endogenous peroxidase was blocked with Immunopure Peroxidase (Pierce). Control IgG antibodies were used at the same concentration as the primary antibodies (R\&D Systems). Following incubation with secondary antibodies (Bio-Rad; either mouse, goat or rabbit HRP conjugated, RT, $30 \mathrm{~min}$ ), samples were washed and developed with the DAB kit (Pierce). Samples were viewed with an Olympus BX60 light microscope at room temperature. Data was recorded with the Spot Flex digital camera, Spot software and brightness/contrast was adjusted with Adobe Photoshop CS.

Paraffin-embedded sections were hydrated from xylene through decreasing alcohols to water, heat treated $\left(90^{\circ} \mathrm{C}\right.$, $10 \mathrm{~min}$ ) in deionized water, and then cooled to room temperature. Samples were blocked as above and primary antibodies, SDF-1 (Santa Cruz; 1:50), SCF (AbCam; $5 \mu \mathrm{g} / \mathrm{mL}$ ) were incubated (block solution, $4^{\circ} \mathrm{C}$, overnight). Secondary antibody was applied (Invitrogen Q11401MP; 1:50, RT, 1 h), and samples were viewed with the Qdot 605 cube on an Olympus BX60 microscope. Samples were documented with the Spot Flex digital camera, Spot software and brightness/ contrast was adjusted with Adobe Photoshop CS.

\section{TRAP protocol}

Hind limbs from week-3 mice were treated as in Histology, adhering to processing times to prevent acid phosphatase degradation. Staining followed the manufacturer's instructions with the Acid Phosphatase, Leukocyte (TRAP) kit (Sigma; 387A-1KT).

\section{Primary cell isolation}

Bone marrow and trabecular bone cells were harvested from week-3 mice, while hypertrophic chondrocytes and calvarial osteoblasts were from day 3 and 7 mice, respectively. (i) For stromal cells, tibiae and femurs were flushed with PBS. Cells were grown in Primary Cell Media (PCM), DMEM (Gibco) with 10\% FBS (Hyclone) and penicillin/ streptomycin (Gibco). (ii) For trabecular bone cells, tibiae were cleaned from skin and muscle, marrow was flushed with PBS, and tibiae were cut at the epiphysis and below the flared metaphysis adjacent to the diaphyses to isolate trabecular bone. An additional cut was then made at the growth plate zone. Isolated bones were incubated in DMEM (Gibco) with collagenase $\mathrm{D}$ (Roche; $3 \mathrm{mg} / \mathrm{mL}$ ) and pronase (Roche; $2 \mathrm{mg} / \mathrm{mL}, 37^{\circ} \mathrm{C}, 10 \mathrm{~min}$, rocking). Media were discarded and bones cut longitudinally to expose trabecular spicules. Samples were digested as above ( $30 \mathrm{~min})$, three times, and cells isolated during each incubation were pooled, pelleted (1000RPM, $5 \mathrm{~min}$ ), washed with PBS, and grown in PCM with $10 \mathrm{mM} \beta$-glycerophosphate and $50 \mu \mathrm{g} / \mathrm{mL}$ ascorbic acid (Sigma). (iii) For calvarial osteoblasts, calvaria were cleaned, and digested in DMEM (Gibco) with collagenase D (Roche; $1 \mathrm{mg} / \mathrm{mL}$ ) and pronase (Roche; $2 \mathrm{mg} / \mathrm{mL}, 37^{\circ} \mathrm{C}, 8 \mathrm{~min}$, rocking). Media were discarded; bones were cut into $\sim 2 \mathrm{~mm}$ pieces, and incubated as above $(10 \mathrm{~min})$, four times. Media were pooled, and osteoblasts were pelleted (1000RPM; $5 \mathrm{~min}$ ), washed with PBS, and grown as in (ii). (iv) With hypertrophic chondrocytes, cleaned ribs were cut along the spine and ossified ends to isolate growth plates. Ribs were incubated in PBS with pronase (Roche; $2 \mathrm{mg} / \mathrm{mL}, 37^{\circ} \mathrm{C}, 30 \mathrm{~min}$ ), then rinsed with PBS and incubated in DMEM (Gibco) with collagenase $\mathrm{D}$ (Roche; $3 \mathrm{mg} / \mathrm{mL}, 37^{\circ} \mathrm{C}$ for $30 \mathrm{~min}$ with agitation). Media were discarded, and ribs were again incubated as above (90 min). Media were collected, passed through a $60 \mu \mathrm{M}$ mesh and spun (1000RPM; $5 \mathrm{~min}$ ) for cell collection. Cells were washed with PBS several times and plated in PCM on a $100 \mathrm{~mm}$ dish (Fisher Scientific) coated in 1.5\% SeaKem GTG agarose (Lonza) dissolved in PBS. Cells were harvested on day 3 , deaggregated in collagenase $\mathrm{D}\left(3 \mathrm{mg} / \mathrm{mL}\right.$ in DMEM, $37^{\circ} \mathrm{C}$ for $30 \mathrm{~min}$ with agitation), washed with PBS several times, and plated in PCM with ascorbic acid (Sigma; $50 \mu \mathrm{g} / \mathrm{mL}$ ) at $10^{5}$ cells $/ \mathrm{cm}^{2}$ for assays.

\section{Coculture assays}

Feeder cells (CD45.2+) enriched for stromal, trabecular bone, and hypertrophic chondrocyte cells were isolated as above. Confluent stromal and trabecular cells were harvested (day 6-9) and plated in six-well plates at $2 \times 10^{6}$ cells/well. Upon $80 \%$ confluency, stromal cells were inactivated with mitomycin C (Sigma) at $10 \mu \mathrm{g} / \mathrm{mL}$ in PCM $\left(37^{\circ} \mathrm{C}, 2 \mathrm{~h}\right)$. Hypertrophic chondrocytes were plated in 12-well plates at $4 \times 10^{5}$ cells per well, and were inactivated with mitomycin C once refractile chondrocytes were formed (4-5 days). Lincells were isolated from marrow aspirates of week-3 B6.SJLPtprc $^{\mathrm{a}} \mathrm{Pepc}^{\mathrm{b}}(\mathrm{CD} 45.1+)$ mice via a Lineage Cell Depletion Kit (Milteni Biotec). Lin- cells were seeded on the feeder layers at $1 \times 10^{5}$ cells per well in a six-well plate and $5 \times 10^{4}$ cells per well in a 12-well plate (Stem Cell Technologies). Cocultures were maintained in assay media, RPMI with 10\% FBS, penicillin/streptomycin, and $50 \mu \mathrm{M} \beta$-mercaptoethanol (Gibco) for 2-4 weeks (see below). For chondrocyte and osteoblast assays, ascorbic acid and b-glycerol phosphate were maintained in the assay media as described in Primary cell isolation. Half media changes were made every 3 days (4 weeks for stromal and 2 weeks for osteoblast and chondrocyte assays). In cytokines supplemented coculture assays, IL-7, SDF-1, and SCF (R\&D systems) mouse recombinant proteins were added at $10 \mathrm{ng} / \mathrm{mL}, 200 \mathrm{ng} / \mathrm{mL}$ and $25 \mathrm{ng} / \mathrm{mL}$, respectively with each media change. Upon assay conclusion, conditioned media were collected for cytokine array and ELISA, or adherent and nonadherent cells were harvested for flow cytometry, washed, and filtered (BD; Falcon cell strainer tubes).

\section{Alcian blue staining}

Chondrocytes were grown as above and sulfated glycosaminoglycans were stained for with alcian blue at $\mathrm{pH} 1$ [48]. Chondrocyte cultures were grown 6 days after harvesting from agarose, fixed with $10 \%$ formaldehyde for $15 \mathrm{~m}$ at $4^{\circ} \mathrm{C}$ and incubated with $1 \%$ alcian blue (Sigma) in $0.1 \mathrm{~N} \mathrm{HCL}$ at $\mathrm{RT}$ for $7 \mathrm{~h}$. The dye solution was removed and plates were air dried. Semi-quantitation was made by adding $6 \mathrm{M}$ guanidine $\mathrm{HCL}$ at $\mathrm{RT}$ for $7 \mathrm{~h}$ with gentle rocking. The OD was then read at $650 \mathrm{~nm}$. 


\section{Quantitative reverse transcriptase-polymerase chain reaction}

As comparison controls (positive for collagen I and negative for ColX) 3T3 cells were grown to confluency and RNA was harvested for quantitative reverse transcriptase-polymerase chain reaction (qRT-PCR). Cells harvested from the calveria, trabecular zone, and ribs were grown as above. In these assays, one well of a six-well dish was used as one sample, and all experimental cell types were grown at three different time points for comparable triplicates. Qiagen protocols for qRT-PCR were followed for generation of $0.5 \mu \mathrm{g}$ total RNA per reaction (RNeasy mini kit, QIAshredder, $\mathrm{RT}^{2}$ profiler PCR array, first strand kit, SYBR green ROX qPCR mastermix). Qiagen primers for collagen I, II, and X, as well as osteopontin, and osteocalcin were used as recommended in PCR reactions on an Applied Biosystems model 7500 (Fast block) PCR machine in 96 well plates $(25 \mu \mathrm{L})$. All plates were run with the same threshold levels and the average $\mathrm{Ct}$ and standard deviation was determined from three different cell isolations per cell type and analysis was done with Qiagen analysis programs (www.sabiosciences.com/ pcrarraydataanalysis.php).

\section{Flow cytometry}

Flow cytometry was performed as described [38]. Briefly, marrow cells were flushed from tibiae and femurs with PBS. Erythrocytes were lysed with ACK buffer $\left(0.15 \mathrm{M} \mathrm{NH} \mathrm{NCl}_{4}\right.$, $10 \mathrm{mM} \mathrm{KHCO}, 0.1 \mathrm{mM} \mathrm{Na}{ }_{2}$ EDTA, pH 7.4, $1 \mathrm{~min}$ ) and cells were resuspended in flow buffer (PBS pH 7.2, 0.5\% BSA, $2 \mathrm{mM}$ EDTA). For cultured cells, A) stromal cell cocultures were harvested in $0.25 \%$ trypsin-EDTA solution (Gibco), B) osteoblast cocultures were harvested in DMEM with $2 \mathrm{mg} /$ $\mathrm{mL}$ collagenase $\mathrm{D}$ and $2 \mathrm{mg} / \mathrm{mL}$ pronase $\left(37^{\circ} \mathrm{C}, 15 \mathrm{~min}\right)$ and C) hypertrophic chondrocyte cocultures were harvested in DMEM with $2 \mathrm{mg} / \mathrm{mL}$ collagenase $\mathrm{D}\left(37^{\circ} \mathrm{C}, 30 \mathrm{~min}\right)$. Isolated cells were labeled in flow buffer with conjugated antibodies $\left(0.2 \mu \mathrm{g} / 10^{6}\right.$ cells): anti-CD45.1, anti-CD45.2, antiCD19, anti-B220, anti-CD43, (BD PharMingen), and anti-IgM (eBioscience). The BD Canto was used with DiVa software for data acquisition and FlowJo software for data analysis. Lymphocyte and granulocyte gates were set with marrow cells from wild type mice. Numbers of cells for coculture assays were calculated per run of 100,000 cells per well.

\section{Cytokine array}

Conditioned media from the coculture assays were incubated with a customized mouse cytokine antibody array membrane from RayBiotech, Inc. Array instructions were followed, membranes were incubated with $1 \mathrm{~mL}$ of pooled conditioned media from wild type and ColX $\mathrm{KO}$ mouse trabecular bone and hypertrophic chondrocyte cocultures \pm lin- cells. Biotin-conjugated antibody cocktail and HRP-conjugated streptavadin antibody was used for detection (RayBioech). Results were imaged with the Fugi Imager LAS 3000 and analyzed with ImageGauge software V4.22 and Excel. For data analysis, media only intensity were subtracted from all sample intensities, samples were averaged, followed by normalization to wild type membrane for comparison between membranes. To assess positive cytokines, normalized sample intensity was compared to media only background controls. Normalized sample intensities were also used to establish ratios between wild type and ColX KO samples, significant changes; + indicates $\geq 1.5$ change over and - indicates $\geq 0.65$ change below wild type levels.

\section{IL-7 injections}

Wild type and ColX-Tg/KO mice were injected intraperitoneally twice daily with $100 \mathrm{ng}$ recombinant IL-7 (R\&D Systems) or vehicle only (PBS with $0.1 \%$ BSA; Sigma) from either day 3-6 or day 17-20. At the conclusion of the experiment, on day 7 or 21, marrow cells were harvested; nucleated cells were counted, and were stained as in Flow cytometry. Numbers of live pro-B (B220+, AA4.1+, IgM-, $\mathrm{CD} 43+)$, pre-B $(\mathrm{B} 220+, \mathrm{AA} 4.1+, \mathrm{IgM}-, \mathrm{CD} 43-)$, early $(\mathrm{B} 220+, \operatorname{IgM}-)$, late $(\mathrm{B} 220+, \operatorname{IgM}+)$, and total B220+ cells were calculated by multiplying the percent positive by the total number of nucleated cells per hind limb. An example of flow cytometry profile can be seen in Supplementary Fig. S2E (Supplementary Data are available online at www .liebertpub.com/scd).

\section{Results}

\section{Micro-CT analysis confirms changes in ColX mouse trabecular bone}

Osteoblasts have been positively associated with B lymphopoiesis, both in vitro and in vivo [14,17-21,49]. Interestingly, in addition to the variable outward disease phenotype of the ColX-Tg/KO, ranging from perinatal lethality (severe), to transient dwarfism or no discernable outward phenotype [38], all ColX-Tg/KO mice have altered B lymphopoiesis throughout life [39-41]. Although histological changes of trabecular bone at the $\mathrm{COJ}$ in the $\mathrm{ColX}-\mathrm{Tg} / \mathrm{KO}$ mice have been documented $[40,41,44]$, the quality of the trabecular bone has not been assessed and might contribute to the diminished B lymphopoiesis in the ColX-Tg/KO mice. Thus, micro-CT analysis was used to measure bone quality within the tibial COJ of all subsets of ColX mice to explore a possible link between altered bone characteristics in the ColX-Tg/KO mice and deficient $\mathrm{B}$ lymphopoiesis. These studies revealed altered bone microstructure and mineralization in the metaphyses and mid-diaphyses, as well as in both proximal ossification sites. Specifically, the ColX-Tg/KO mice displayed decreased bone volume and reduced connectivity in the metaphysis, decreased bone volume and increased trabecular number in the epiphysis, and significantly lower cortical bone volume, average cortical thickness, and average cross-sectional area in the mid-diaphysis (Table 1). Moreover, the ColX-Tg/KO mice with the severe outward phenotype, especially ColX-Tg-severe mice, displayed the most significant changes in bone volume, volume fraction, trabecular thickness, and connectivity density in all regions assayed (Supplementary Fig. S1A), and have the most severely diminished B cell numbers [38-40].

To discount the possible contribution of the mesenchymal stromal cells to diminished bone at the COJ, marrow cell proliferation, CFU-F/ALP and CFU-O colony formation assays were preformed with the $\mathrm{ColX}-\mathrm{Tg} / \mathrm{KO}$ and wild type mice. These assays showed no significant differences in proliferation, CFU-F/ALP and CFU-O colony formation 
Table 1. Micro-Computed Tomography Analysis of Long Bones from Week-3 Wild Type and Collagen X Null and Transgenic Mice

\begin{tabular}{|c|c|c|c|c|c|c|c|c|c|}
\hline & $\begin{array}{l}\text { Bone } \\
\text { volume } \\
\left(\mathrm{mm}^{3}\right)\end{array}$ & $\begin{array}{l}\text { Total } \\
\text { volume } \\
\left(\mathrm{mm}^{3}\right)\end{array}$ & $\begin{array}{c}\text { Mineralized } \\
\text { volume } \\
\text { fraction }\end{array}$ & $\begin{array}{c}\text { Average } \\
\text { trabecular } \\
\text { thickness }(\mathrm{mm})\end{array}$ & $\begin{array}{c}\text { Average } \\
\text { trabecular } \\
\text { separation }(\mathrm{mm})\end{array}$ & & $\begin{array}{l}\text { rage trabecular } \\
\text { umber/density } \\
(1 / \mathrm{mm})\end{array}$ & $\begin{array}{c}\text { Connectivity } \\
\text { density } \\
\left(1 / \mathrm{mm}^{3}\right)\end{array}$ & $\begin{array}{c}\text { Average mineral } \\
\text { density } \\
\left(m g \mathrm{HA} / \mathrm{cm}^{3}\right)\end{array}$ \\
\hline \multicolumn{10}{|l|}{ Epiphysis } \\
\hline WT & 0.0449 & 0.3672 & 0.1213 & 0.0335 & 0.1320 & & 8.8259 & 177.5158 & 714.9133 \\
\hline $\mathrm{Col} \times \mathrm{KO}$ & 0.0352 & 0.3730 & $0.0946^{\mathrm{a}}$ & 0.0328 & 0.1319 & & 8.9362 & 121.4537 & 736.5510 \\
\hline Col X Tg & $0.0214^{\mathrm{a}}$ & $0.1946^{b}$ & 0.1040 & 0.0336 & 0.1264 & & $9.4154^{\mathrm{a}}$ & 148.6887 & 715.1765 \\
\hline \multicolumn{10}{|l|}{ Metaphysis } \\
\hline WT & 0.0326 & 0.5157 & 0.0629 & 0.0355 & 0.2349 & & 4.6643 & 53.4683 & 679.3226 \\
\hline $\mathrm{Col} \times \mathrm{KO}$ & 0.0311 & $0.5984^{a}$ & 0.0519 & $0.0322^{\mathrm{a}}$ & 0.2275 & & 4.6168 & $25.0357^{\mathrm{a}}$ & 645.2098 \\
\hline Col X Tg & $0.0190^{\mathrm{a}}$ & 0.4187 & 0.0427 & 0.0332 & 0.2580 & & 4.2059 & $23.7735^{\mathrm{a}}$ & 688.8751 \\
\hline \multicolumn{10}{|l|}{$\begin{array}{l}\text { Metaphyseal } \\
\text { cortical }\end{array}$} \\
\hline WT & 0.3459 & 0.5284 & 0.6508 & NA & NA & & NA & NA & 675.4504 \\
\hline $\mathrm{Col} \times \mathrm{KO}$ & 0.3350 & 0.5566 & 0.6006 & NA & NA & & NA & NA & 656.7533 \\
\hline \multirow[t]{2}{*}{$\mathrm{Col} \times \mathrm{Tg}$} & $0.2079^{\mathrm{a}}$ & $0.4045^{\mathrm{a}}$ & $0.4950^{\mathrm{a}}$ & NA & NA & & NA & NA & 668.5061 \\
\hline & \multicolumn{2}{|c|}{$\begin{array}{l}\text { Bone volume } \\
\qquad\left(\mathrm{mm}^{3}\right)\end{array}$} & \multicolumn{2}{|c|}{$\begin{array}{l}\text { Average cortical } \\
\text { thickness }(\mathrm{mm})\end{array}$} & \multicolumn{4}{|c|}{$\begin{array}{c}\text { Cross-sectional } \\
\text { area }\left(\mathrm{mm}^{2}\right)\end{array}$} & $\begin{array}{l}\text { Maximum moment } \\
\text { of inertia }\left(\mathrm{mm}^{4}\right)\end{array}$ \\
\hline \multicolumn{10}{|c|}{ Mid-diaphysis } \\
\hline \multirow{3}{*}{\multicolumn{2}{|c|}{$\begin{array}{l}\text { WT } \\
\text { Col X KO } \\
\text { Col X Tg }\end{array}$}} & 0.4327 & \multicolumn{2}{|c|}{0.1234} & 1003.0678 & \multicolumn{3}{|c|}{0.2799} & 0.0209 \\
\hline & & $0.3666^{\mathrm{a}}$ & \multicolumn{2}{|c|}{$0.0971^{\mathrm{b}}$} & 1019.2992 & \multicolumn{3}{|c|}{$0.2383^{\mathrm{a}}$} & 0.0195 \\
\hline & & $0.2949^{b}$ & \multicolumn{2}{|c|}{$0.0948^{\mathrm{a}}$} & 1008.0237 & \multicolumn{3}{|c|}{$0.1917^{\mathrm{b}}$} & $0.0105^{\mathrm{b}}$ \\
\hline
\end{tabular}

${ }^{\mathrm{a}} P<0.05$.

${ }^{\mathrm{b}} P<0.001$.

WT, wild type; Col X KO, collagen X null; $\mathrm{Col} X \mathrm{Tg}$, collagen $\mathrm{X}$ transgenic; NA, not applicable.

between the ColX-Tg/KO and wild type (Fig. 1A-C). Further, to exclude the osteoclast as a contributor to the aberrant micro-CT findings, tibiae were stained for tartrate resistant acid phosphatase (TRAP), an indicator of osteoclast bone resorptive activity. Although increased TRAP staining was observed in the trabecular and cortical regions of the ColXsevere mice that were cachectic (Supplementary Fig. S1B; [35]), no significant increase in TRAP staining was observed in the major subset of the ColX-Tg/KO mice (Fig. 1D). These data suggest that the lack of functional ColX does not lead to changes in stromal cell proliferation, colony formation and mineralization, or osteoclast activity. Of note, in agreement with the micro-CT data, reduced trabecular length was measured in all subsets of ColX-Tg/KO mice compared to wild type (Fig. 1D and Supplementary Fig. S1B).

\section{Trabecular bone cells from ColX mice are defective in support of B lymphopoiesis}

The observed micro-CT changes in the ColX-Tg/KO mice, coupled with diminished trabecular bone and an altered hypertrophic cartilage matrix [36], likely contribute to a defective hematopoietic environment and diminished B lymphopoiesis, as reported in other models [14,17-21,49]. Thus, to further investigate the relationship between the bone and cartilage defects and aberrant lymphopoiesis, COJ derived cell types, including stromal cells, trabecular bone cells, and hypertrophic chondrocytes, were tested for their ability to support B lymphopoiesis in coculture assays. Specifically, the different COJ cell types served as feeder layers for hematopoietic progenitor cell (HPC) growth and differentiation, similar to classic long-term culture-initiating cell assays [50]. The CD45.1 verses CD45.2 markers, and B-cell (CD 19) and granulocyte (GR-1) markers enabled a cytometric analysis for feeder layer verses HPC cell differentiation. Since we had previously observed no quantitative differences between wild type and ColX-Tg/KO HPC, consistent with lack of an affect of altered ColX function on the primitive hematopoietic stem cell (HSC) population [39], wild type lineage negative (lin-) donor cells were held constant throughout these assays. Additionally, the ColX-Tg mice were not used in the coculture studies to avoid COJ cells derived from mice expressing mutated ColX trimers [35]. As a result, the feeder layers used in these studies were derived from either an in vivo environment with control levels of ColX, or a complete absence of ColX [41,51]. Finally, sorting for primitive HSCs was not performed since the goal of these assays was to assess the ability of the COJ cells to support hematopoietic outgrowth, and not to directly measure the ability of COJ cells to induce early stem cell differentiation, maintenance or quiescence.

Several controls were used in these coculture assays. First, the donor B6-SJL (CD45.1 + ) lin- population was assessed via flow cytometry to confirm a reduction in the number of lin + cells to avoid false positive results (Supplementary Fig. S2A). Second, either feeder layers without the addition lin- cell, or lin- cells without feeder layers were used for negative read-out controls (Supplementary Fig. S2B). Third, stromal cell feeder layers, which have been used extensively to study HPC differentiation [50], were used as a positive read-out of B lymphopoiesis (Supplementary Fig. S2D). Additionally, previous studies that had linked osteoblast and B cell development in vitro had focused exclusively on 

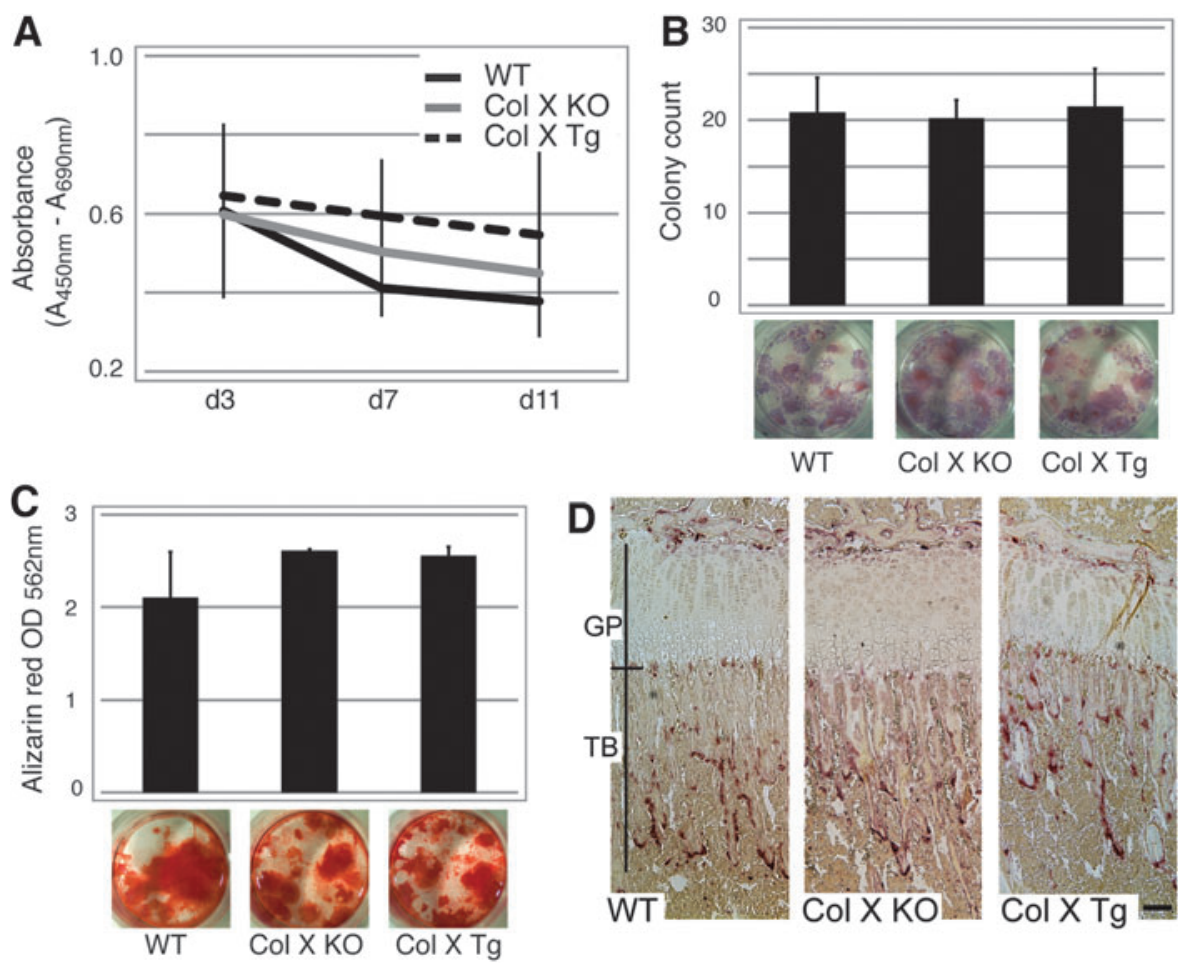

FIG. 1. Marrow stromal cell and osteoclast characterization. (A) Proliferation assay with marrow stromal cells from week-3 wild type (WT) and collagen $\mathrm{X}$ null and transgenic mice (Col X KO, Col X Tg; $n=4$, in 8 replicates). (B) Colony-forming unit alkaline phosphatase (CFU-ALP) colony counts and representative culture plate views depicting purple ALP staining of week-3 WT, Col X KO and Col X Tg mouse cells after 14 days of culture $(n=4)$. (C) Colony-forming unit osteoblast (CFU-O) colony semi-quantification and representative culture plate views depicting Alizarin red S staining of week-3 WT, Col X KO, and Col X Tg mouse cells after 21 days in culture with ostogenic media $(n=4)$. (D) Tibial longitudinal sections from week-3 WT, Col X KO and Col X Tg mice were reacted with tartrate-resistant acid phosphatase (TRAP; red color) for osteoclast activity. Growth plate (GP) and trabecular bone (TB) of the chondro-osseous junction are bracketed. While no discernable differences in TRAP staining or osteoclast distribution were noted, the average length of trabecular spicules was longer in WT mice $(403.75 \mu \mathrm{M}, n=4)$ than in $\mathrm{Col} \mathrm{X} \mathrm{KO}$ and Tg mice (340.75 and $291.75 \mu \mathrm{M}, n=4$, respectively). Bar $=100 \mu \mathrm{M}$.

osteoblasts derived from the calvaria, which develop by intramembranous ossification (IO). During IO, cells differentiate directly from mesenchymal cells to osteoblasts, resulting in dense bone $[18,21,49,52]$. Thus, IO-derived calvaria cocultures were included in our studies as positive controls, as well as for an assessment of IO- verses EO-derived osteolineage cells in the support of B lymphopoiesis.

The isolation and maintenance of the feeder layers was optimized for these coculture assays, and cell-specific phenotypes were verified by multiple approaches, including: morphology; staining for collagen I, osteocalcin and osteopontin (osteoblast-like markers), and collagen II and X (chondrocytelike markers) (Fig. 2A-C); semi-quantification of mineralization (trabecular and calvaria cultures); presence of sulfated proteoglycans (chondrocyte cultures) (Fig. 2D); and quantification of chondro-oseous marker expression via qRT-PCR (Fig. 2E). In qRT-PCR assays, 3T3 fibroblasts were used as positive controls for collagen I, and as negative controls for ColX expression. The qRT-PCR assays confirm no statistical differences between the wild type and ColX-Tg/KO chondroosseous cells, except for the osteocalcin expression between the wild type and ColX-Tg/KO trabecular culture $(P<0.005)$ and, as expected, ColX expression. Additionally, these data corroborate a similar chondro-osseous phenotype between the different osteoblast and hypertrophic chondrocyte cell types.
Overall, granulopoiesis (Gr-1+) was not reduced in cocultures using any of the ColX-KO derived feeder layers, compared to wild type feeder layers (Fig. 3B), which correlates with previous flow cytometric analyses of marrow aspirates from ColX-Tg mice [40]. Additionally, wild type and ColX-KO stromal cells showed comparable support of lymphocyte $(\mathrm{CD} 19+)$ cells (Supplementary Fig. S2D). Of note, no decrease in CD19 + cell outgrowth was observed in the IO-derived calvaria cocultures from ColX-KO mice compared to wild type mice (Fig. 3A), confirming that IO-derived osteoblasts are not affected by a lack of ColX expression. However, in contrast, B cell outgrowth was significantly reduced in the ColX-KO EO-derived trabecular cocultures (Fig. 3A). Interestingly, the numbers of granulocytes reciprocally increased ColX-KO EO-derived trabecular cocultures (Fig. 3B), after a relationship between lymphocyte numbers and granulocyte numbers that has been observed in RAG - / mice and during inflammation, leading to the proposed common developmental niche for lymphocytes and granulocytes in mice [53]. Further, it is noteworthy that both wild type and ColX-KO mouse derived hypertrophic chondrocyte cultures, previously not associated with hematopoiesis, could also support both CD19+ and Gr-1+ cell outgrowth from progenitor cells after coculture, albeit equally well (Fig. 3A, B). 

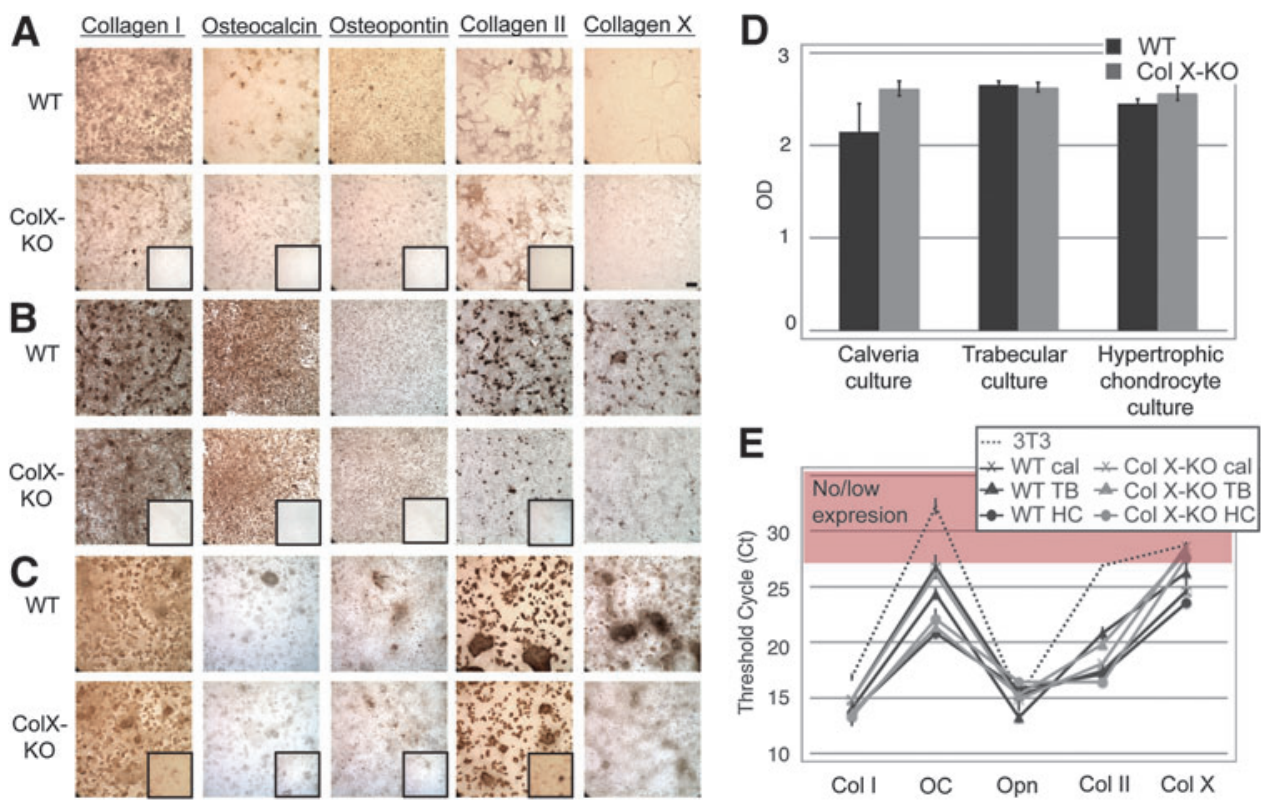

FIG. 2. Characterization of cocultures with calvaria, trabecular and hypertrophic chondrocyte cells. Calvaria (A), trabecular (B) and hypertrophic chondrocyte (C) cocultures from WT and collagen X null (ColX-KO) mice were grown to confluency and cell-specific phenotypes were assessed by staining with antibodies for: collagen I, collagen II, collagen X, osteocalcin, and osteopontin. IgG controls are boxed on $\mathrm{KO}$ samples except for collagen $\mathrm{X}$ staining where the $\mathrm{KO}$ mice serve as controls. Magnification $10 \times, \mathrm{Bar}=200 \mu \mathrm{M}$. (D) WT and Col X-KO mouse calveria and trabucular cultures were stained with Alizarin red S for mineralization, followed by quantitation of solubilized stain (OD 562). Chondrocyte cultures were stained with alcian blue, followed by quantitation of solubilized stain (OD 650) for identification of sulfated proteoglycans characteristically present in cartilage. (E) Expression of chondro-oseous markers (collagen I (Col I), osteocalcin (OC), osteopontin (Opn), collagen II ( $\mathrm{Col}$ II), and collagen X ( $\mathrm{Col} \mathrm{X)}$ were assessed by quantitative reverse transcriptase-polymerase chain reaction (qRT-PCR) in 3T3 fibroblasts, as well as in both WT and Col X-KO mouse calvaria (cal), trabecular (TB), and hypertrophic chondrocyte $(\mathrm{HC})$ cultures. Genes with no to low expression fall in the red zone. Note, both cartilage and bone characteristics in all four cell types (B, E).

\section{EO-derived trabecular cells from ColX KO mice have altered cytokine secretion}

Cytokines implicated in B cell support were measured from trabecular coculture supernatants as possible contributors to the poor CD19+ cell outgrowth in the ColX-KO trabecular cocultures (Fig. 3). Interlukin-7 is a well studied cytokine in B cell development; however, even though several IL-7 ELISA kits were tried, none were sensitive enough to detect IL-7 in the conditioned media of the cocultures, for example, an IL-7 ELISA kit that has sensitivity to $3.5 \mathrm{pg} / \mathrm{mL}$, nor were these ELISAs sensitive enough to measure IL-7 directly from wild type mouse marrow supernatants [54] (Supplementary Fig. S3A, B). However, SDF-1 and SCF ELISA kits did show decreases in these early B cell development cytokines in the conditioned media of ColX-KO trabecular cocultures compared to wild type (Supplementary Fig. S3A). Subsequently, more sensitive cytokine arrays from RayBiotech revealed decreases in many hematopoietic cytokines (including IL-7) from the ColX-KO trabecular cocultures compared to wild type. Of these cytokines, many are involved in B lymphopoiesis: SCF, IL-7, SDF-1, Flt-3L, TSLP, IL-3, 4, 5, 6, 10, and IL-11, (Table 2; ordered from early, to late, to no reported affect on B cell development), suggesting a link between reduced cytokine signaling and diminished B cell outgrowth in the ColX-KO trabecular cocultures. Cytokine arrays with wild type and ColX-KO hypertrophic chondrocyte coculture supernatants, which both supported
CD19+ cell outgrowth equally well (Fig. 3A), showed no decreases in these B lymphopoietic cytokines (Table 2). Moreover, the cytokine arrays confirmed secretion of hematopoietic cytokines by both the trabecular and hypertrophic chondrocyte cultures, which supports our hypothesis that these EO-derived COJ cells are active players in the hematopoietic niche (Table 2) [42].

\section{ColX mice have altered staining for SCF and SDF-1 at the COJ}

Next, to confirm the altered cytokine secretion in vivo in the ColX-Tg/KO mice, the early B cell cytokines IL-7, SCF, and SDF-1 $[55,56]$ were immunolocalized to the COJ. However, attempts to detect IL-7 in tibio-femoral bone sections were unsuccessful, despite use of various embedding protocols and several different IL-7 specific antibodies, which was consistent with previous reports [34]. Conversely, both SCF and SDF-1 showed localization differences and diminished immunoreactivity within the COJ of ColX-Tg/KO mice (Fig. 4B, C). In wild type sections, SCF was localized to the pre- and terminal hypertrophic chondrocytes, osteoblasts, and bone lining cells along trabecular bone surfaces, including marrow cells (Fig. 4A). Staining for SCF was reduced in the hypertrophic chondrocytes of the ColX-Tg/KO samples, especially in the terminal hypertrophic chondrocytes, and was overall decreased throughout the trabecular bone region (Fig. 4B, C). SDF-1 in wild type sections presented as a 
FIG. 3. Coculture assays confirm a defect in the ability of collagen $X$ mouse trabecular cocultures to support B lymphopoiesis. (A) The number of CD45.1+ (donor) CD19 (B cell marker) cells was determined from trabecular, calvarial, and hypertrophic chondrocyte cocultures from WT or collagen $X$ null (Col X-KO) mice. (B) The number of CD45.1+ (donor) Gr-1 (granulocyte marker) cells was also determined from the same coculture experiments. Cells were analyzed 2 weeks post seeding of WT lineage negative cells. Standard error of the mean shown for $>10$ wells from multiple experiments per group.

\section{A $\frac{2}{2}$}
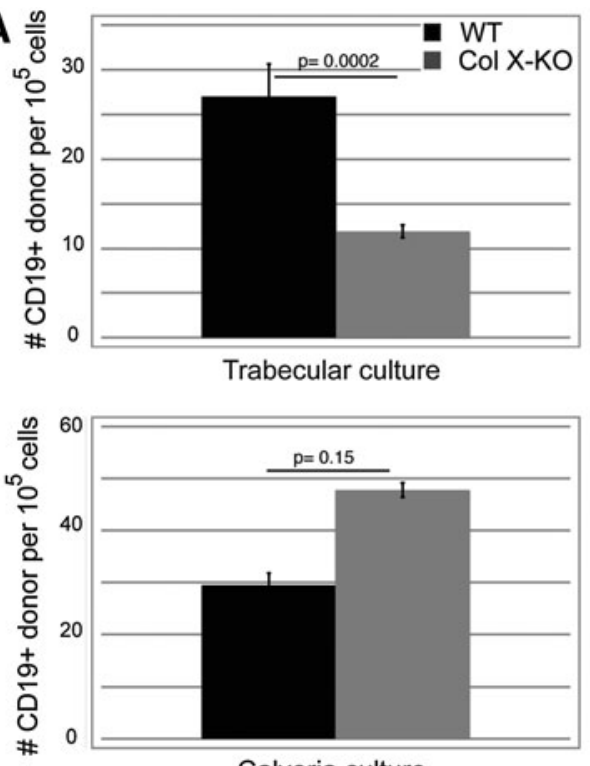

Calveria culture

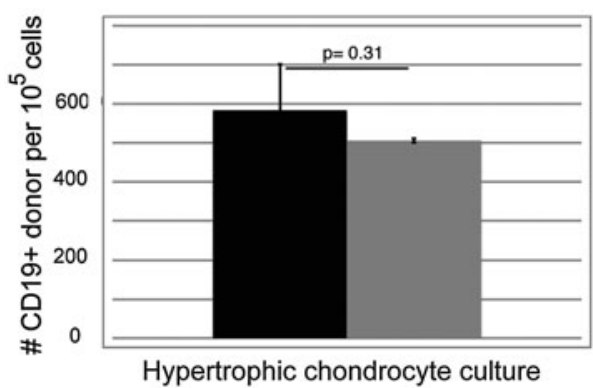

B
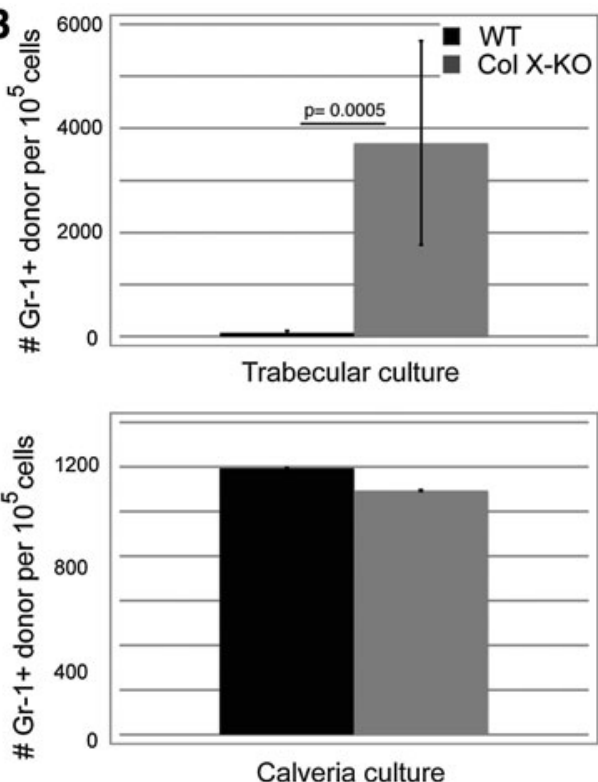

Calveria culture

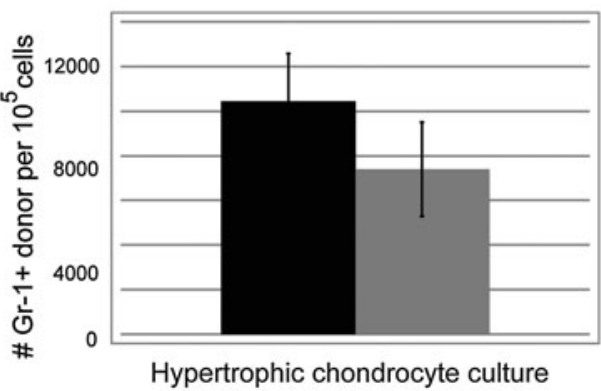

"halo" around terminal hypertrophic chondrocytes, and stained cells along trabecular bone surfaces and marrow cells, similar to SCF staining (Fig. 4A). In the ColX-Tg/KO mice, the SDF-1 "halo" around terminal hypertrophic chondrocytes was neither as intense nor as frequent; further, the overall staining intensity for SDF-1 was decreased along the trabeculae (Fig. 4B, C).

\section{Exogenous cytokine restores $B$ lymphopoiesis in ColX mouse cocultures and in vivo}

The immunohistochemistry data supports the coculture cytokine array data, suggesting that the diminished B cells in the ColX-Tg/KO mice may be due, in part, to altered $\mathrm{B}$ lymphopoietic cytokine secretion and/or sequestration at the COJ. Thus, to further explore whether lower levels of IL-7, SCF and/or SDF-1 in ColX-KO trabecular cocultures resulted in diminished B cell outgrowth, recombinant cytokines were added to the coculture media individually and in combination, followed by assessment of CD19+ and Gr-1 + cells. Of note, the addition of IL-7, SCF and SDF-1 had no affect on the chondro-osseous phenotype of the trabecular cultures, as measured by collagen I, II and X, as well as osteocalcin and osteopontin expression (Fig. 5A), and by collagen I and osteopontin staining (Fig. 5B). However, the addition of IL-7, SCF, and SDF-1 did restore CD19+ cell outgrowth in the ColX-KO trabecular cocultures to wild type levels, with the most robust outgrowth in response to IL-7 (Fig. 5C). Further, the addition of IL-7, SCF, and SDF-1 also stimulated Gr-1+ cell outgrowth in the wild type and ColX-KO trabecular cocultures, with the most robust outgrowth in response to SCF (Fig. 5D). Similar hematopoietic stimulation was observed when these cytokines were added in combination (data not shown).

Taken together, these data suggest that a lack of hematopoietic cytokine production by the EO-derived trabecular bone cell cultures might contribute to the decreased $\mathrm{B}$ cell numbers measured in vivo [39-41]. To further link the reduction of cytokines at the ColX-Tg/KO mouse COJ to decreased B lymphopoiesis, recombinant IL-7 was injected into wild type, ColX-KO and ColX-Tg mice followed by assessment of marrow B lymphopoiesis. Although several cytokines have been linked to B cell development, IL-7 was chosen since it had the most pronounced affect on B cell outgrowth in vitro (Fig. 5C). Of note, the percentage of IL-7 receptor positive marrow cells was similar between ColX$\mathrm{Tg} / \mathrm{KO}$ and wild type mice (Supplementary Fig. S3C), suggesting that ColX-Tg/KO mouse marrow cells have similar capability to respond to IL-7 signaling as wild type mice. Additionally, the concentration of IL-7 injected and duration of the assay were reduced from previous reports [57,58], and was similar to that used in Wu et al., to avoid over saturation of cytokine [20]. In agreement with noninjected day 7 and day $21 \mathrm{ColX}-\mathrm{Tg} / \mathrm{KO}$ mice, the overall number of $\mathrm{B}$ cells in the marrow of ColX-Tg/KO mice were significantly reduced compared to wild type mice after vector only injections 
Table 2. Cytokine Array Analysis of Collagen X

Null Verses Wild Type Trabecular Bone and

Hypertrophic Chondrocyte Derived CoCulture

Media With or Without Lineage Negative Cells

\begin{tabular}{|c|c|c|c|c|c|}
\hline$H S P G$ & Cytokines & $T B$ & $H C$ & $T B+\operatorname{lin}-$ & $H C+\operatorname{lin}-$ \\
\hline & SCF & - & & - & \\
\hline$\sqrt{ }$ & IL-7 & - & & - & \\
\hline \multirow[t]{3}{*}{$\sqrt{ }$} & SDF-1 $\alpha$ & - & + & - & - \\
\hline & Flt-3L & + & + & & \\
\hline & TSLP & & & & \\
\hline$\sqrt{ }$ & IL-10 & - & & & \\
\hline$\sqrt{ }$ & IL-12p70 & - & & & \\
\hline \multirow[t]{2}{*}{$\sqrt{ }$} & IL-12p40 & - & & & + \\
\hline & IL-11 & - & & & \\
\hline$\sqrt{ }$ & IL-6 & - & + & - & - \\
\hline$\sqrt{ }$ & IL-5 & - & & - & \\
\hline$\sqrt{ }$ & IL-4 & - & & - & \\
\hline \multirow[t]{3}{*}{$\sqrt{ }$} & IL-3 & - & & - & \\
\hline & IL-9 & - & & - & \\
\hline & IL-13 & & & & \\
\hline$\sqrt{ }$ & IL-2 & + & + & 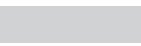 & \\
\hline$\sqrt{ }$ & G-CSF & & & 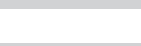 & \\
\hline$\sqrt{ }$ & VEGF & - & & - & \\
\hline$\sqrt{ }$ & 6Ckine & - & & 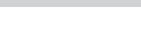 & \\
\hline \multirow[t]{2}{*}{$\sqrt{ }$} & bFGF & - & & & \\
\hline & M-CSF & - & + & - & \\
\hline$\sqrt{ }$ & TARC & - & & - & \\
\hline$\sqrt{ }$ & RANTES & - & + & - & - \\
\hline \multirow[t]{2}{*}{$\sqrt{ }$} & MIP-2 & & & - & \\
\hline & leptin & & & - & \\
\hline$\sqrt{ }$ & IL-1 $\alpha$ & + & + & & \\
\hline$\sqrt{ }$ & IL-1 $\beta$ & + & + & 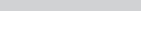 & \\
\hline$\sqrt{ }$ & PF-4 & + & + & + & + \\
\hline \multirow[t]{2}{*}{$\sqrt{ }$} & СТАСК & + & & & \\
\hline & pro-MMP9 & + & + & & \\
\hline \multirow[t]{4}{*}{$\sqrt{ }$} & IFN- $\gamma$ & & & + & + \\
\hline & IL-15 & & & + & \\
\hline & BLC & & + & + & + \\
\hline & Resistin & & + & + & + \\
\hline$\sqrt{ }$ & MCP-1 & & & & \\
\hline \multirow[t]{4}{*}{$\sqrt{ }$} & GM-CSF & & & & + \\
\hline & LIX & & & & \\
\hline & CXCL16 & & + & & + \\
\hline & IL-17 & & + & & \\
\hline$\sqrt{ }$ & CRG-2 & & & & \\
\hline
\end{tabular}

$\sqrt{ }$ indicates cytokines that bind to HSPG. Cytokines are ordered from early, to late, to no reported involvement in B cell development.

SCF, stem cell factor; IL, interleukin; SDF-1, stromal derived factor-1; Flt-3L, FMS-like tyrosine kinase 3 ligand; TSLP, thymic stromal derived lymphopoietin; G-CSF, granulocyte colony stimulating factor; VEGF, vascular endothelial growth factor; bFGF, basic fibroblast growth factor; M-CSF, macrophage colony stimulating factor; TARC, thymus and activation regulated chemokine; MIP, macrophage inflammatory protein; $\mathrm{PF}$, platelet factor; CTACK, cutaneous $\mathrm{T}$ cell attracting chemokine; MMP, matrix metaloproteinase; IFN, interferon; BLC, B lymphocyte chemoattractant; $\mathrm{MCP}$, monocyte chemotactic protein; GM-CSF, granulocyte macrophage colony stimulating factor; LIX, lipopolysaccharide induced CXC chemokine; CRG-2, cytokine responsive gene 2; TB, trabecular bone, $\mathrm{HC}$, hypertrophic chondrocytes; lin, lineage negative; - , decreased compared WT, +, increased compared to WT; HSPG, heparan sulfate proteoglycans.
(Fig. 6) [39-41]. However, after 4 days of IL-7 injections in 1week-old mice the number of pro-B cells and total B220 cells in the $\mathrm{ColX}-\mathrm{Tg} / \mathrm{KO}$ mice was rescued to wild type levels (Fig. 6A, B). Similarly, in 3 week old mice, which are in a period of active skeletogenesis and growth plate turnover, the early stage $B$ cells were likewise rescued to wild type levels after IL-7 injections (Fig. 6C).

\section{Discussion}

In this study, we confirmed an altered EO-derived trabecular bone environment in the ColX-Tg/KO mice via micro-CT (Table 1 and Supplementary Fig. S1), with no associated changes in marrow stromal cell proliferation, CFU-F/ALP, or CFU-O formation (Fig. 1A-C). Additionally, coculture assays implicated the EO-derived trabecular bone cells as the COJ cells from the ColX-KO mice with diminished ability to support B lymphopoiesis (Fig. 3A), and revealed decreased levels of hematopoietic cytokines as a possible cause of altered hematopoiesis in the ColX-Tg/KO mice (Figs. 4-6). These data are consistent with those from several other mouse models that have either increased or decreased osteoblast numbers, or altered osteoblast quality / function, which resulted in changes in B lymphopoiesis $[14,17,19,20,22,23,59]$. Moreover, a crosstalk between bone homeostasis and B cells that involves IL-7 and cytokine signaling has recently been documented $[60,61]$. Specifically, IL7 null mice exhibit both a decrease in trabecular bone mass, as well as decreased numbers of early B cells. In contrast, mice that over-express human IL-7 in collagen I producing cells have both increased trabecular bone mass, as well as increased numbers of early B cells in the marrow [60]. Furthermore, crossing the IL-7 null mice with the Col-I IL-7 Tg mice results in a rescue in bone mass as well as a rescue of $\mathrm{B}$ cell numbers, and directly correlates an increase in bone mass with positive effects on B cells [60]. It has been proposed that under basal conditions, bone homeostasis is maintained via the ratio of the pro-osteoclastogenic factor receptor activator of nuclear factor kappa-b ligand (RANKL) and the anti-osteoclastogenic factor osteoprotegrin. Indeed, marrow B cells at all stages make osteoprotegrin, and are the source of approximately $40 \%$ of all marrow-derived osteoprotegrin [62]. Moreover, B cell deficient mice are osteopenic, further supporting the idea that B cells are anti-osteoclastogenic [62]. Since the ColX-Tg/KO mice generally have diminished B cells throughout life [38-40,42] and reduced secretion of IL-7 from trabecular derived cultures (Table 2), the diminished bone mass quantified by micro-CT in the ColX mice (Table 1 and Supplementary Fig. S1) may be due, in part, to the coupling between B cells, cytokines and bone homeostasis.

Second, the coculture assays not only confirmed that wild type stromal cells and IO-derived osteoblasts can support hematopoiesis [18,21,49,50] (Fig. 3 and Supplementary Fig. S2D), but also demonstrated that wild type EO-derived trabecular and hypertrophic chondrocyte cultures can also support lympho- $(\mathrm{CD} 19+)$ and myelopoiesis (Gr-1+) (Fig. $3)$. These data expand on the hematopoietic niche paradigm, which currently includes IO-derived osteoblasts [12-14,21], stromal cells [27-32], and perivascular mesenchymal cells [24-26], by including EO-derived trabecular bone cells and hypertrophic chondrocytes as additional cellular players within the hematopoietic niche. Overall, our finding that 
FIG. 4. Localization of SCF and SDF-1 in tibiae of WT and collagen $X$ mice. Longitudinal sections from week-3 WT (A), collagen $X$ null $(\mathrm{Col} X-\mathrm{KO})(\mathrm{B})$ and collagen $X$ transgenic $(\mathrm{Col} X-\mathrm{Tg})(\mathrm{C})$ tibiae were stained with hematoxylin and eosin $(\mathrm{H} \& \mathrm{E})$, or with either anti-SCF or anti-SDF-1 antibodies. Arrows indicate the growth plate (GP) and trabecular bone (TB) juncture. Q-dot rabbit controls are boxed. Note SCF localization to osteoblasts and bone lining cells along the trabecular bone and to osteocytes within trabecular bone. In WT, SDF-1 staining in the surrounding territorial matrix of terminal hypertrophic chondrocytes, as well as staining of osteoblasts and bone lining cells, but not osteocytes. In collagen $X$ null and transgenic mice, note overall decrease in staining intensity. Bar $=100 \mu \mathrm{M}, \mathrm{Bar}=50 \mu \mathrm{M}$ in high magnification (high mag) views of SDF-1 staining.
A
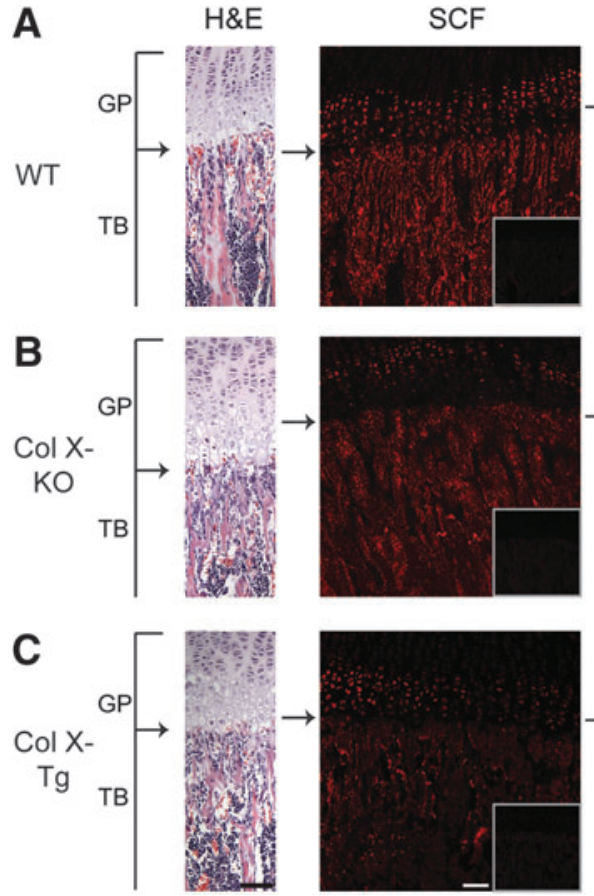

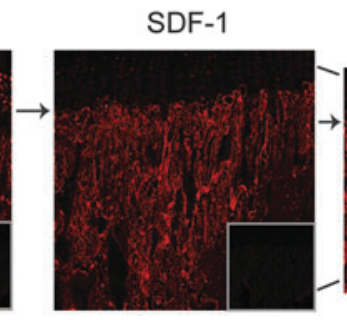

SDF-1
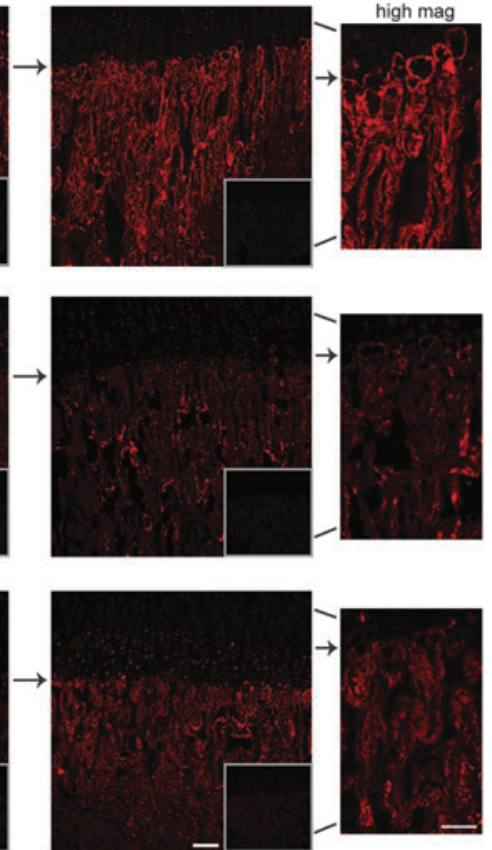

EO-derived trabecular bone cells play a role in support of hematopoietic progenitor cell differentiation, specifically $\mathrm{B}$ cells, highlights the involvement of the ColX-containing cartilaginous step in endochondral skeletogenesis, and implicates the COJ matrix as a constituent in the niche envi- ronment. Consistent with this, we did not see reduced hematopoietic cell outgrowth in cocultures with the IOderived calvarial cells from the ColX-KO mice, presumably due to the lack of/low level of cartilage/ColX production during IO in vivo [52,63-66] (Fig. 3).
A
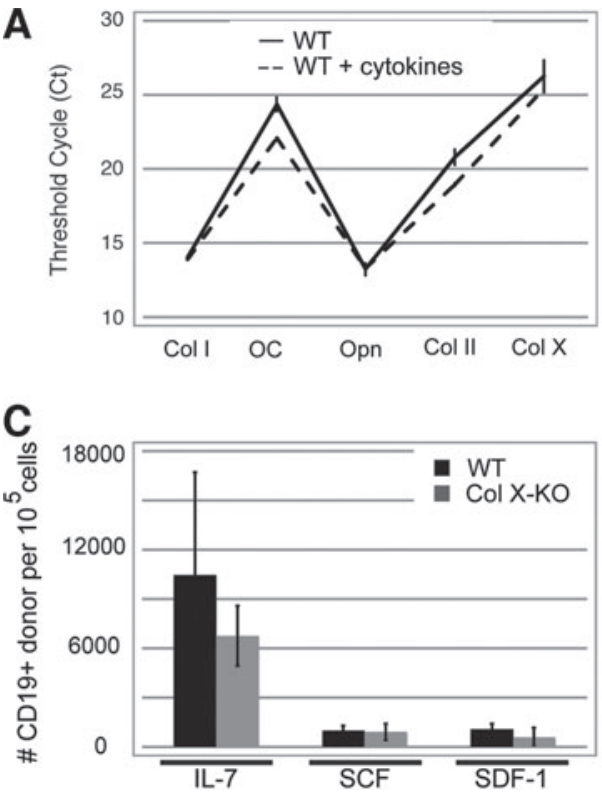

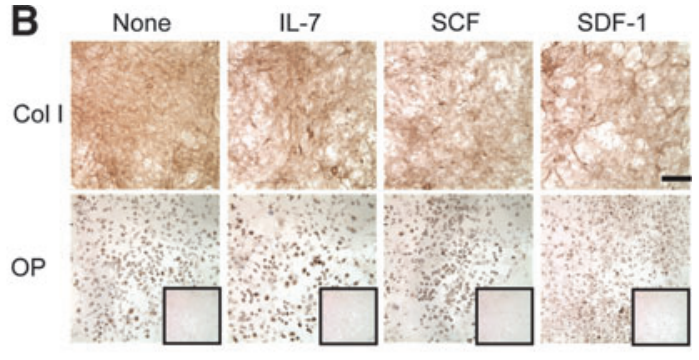

D

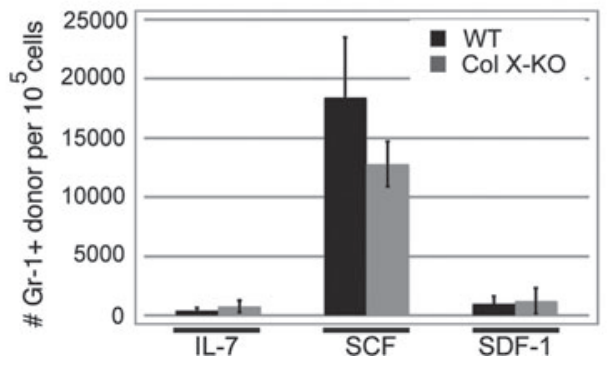

FIG. 5. Cytokine supplementation to trabecular cultures does not change chondro-osseous protein levels and rescues B lymphopoeisis in collagen X null cultures. (A) qRT-PCR was performed for the chondro-osseous markers collagen I (Col I), osteocalcin (OC), osteopontin (Opn), collagen II (Col II), and collagen X (Col X), following supplementation of WT trabecular cultures with IL-7, SCF, and SDF-1 (cytokines). (B) Immunostaining of WT trabecular cultures for collagen I (Col I) and osteopontin (OP) following supplementation with IL-7, SCF and SDF-1. Antibody controls are boxed in OP frames. Magnification 10×, bar $=200 \mu \mathrm{M}$. (C, D) Quantitation of CD45.1 + (donor) CD19 (B cell marker) or Gr-1 (granulocyte cell marker) cells in WT and collagen X null (Col X-KO) mouse trabecular cultures following supplementation with IL-7, SCF, or SDF-1. Note the rescue of CD19+ cell outgrowth in Col X-KO trabecular cocultures after cytokine addition. Standard error of the mean shown for greater than five wells from multiple experiments per group. 

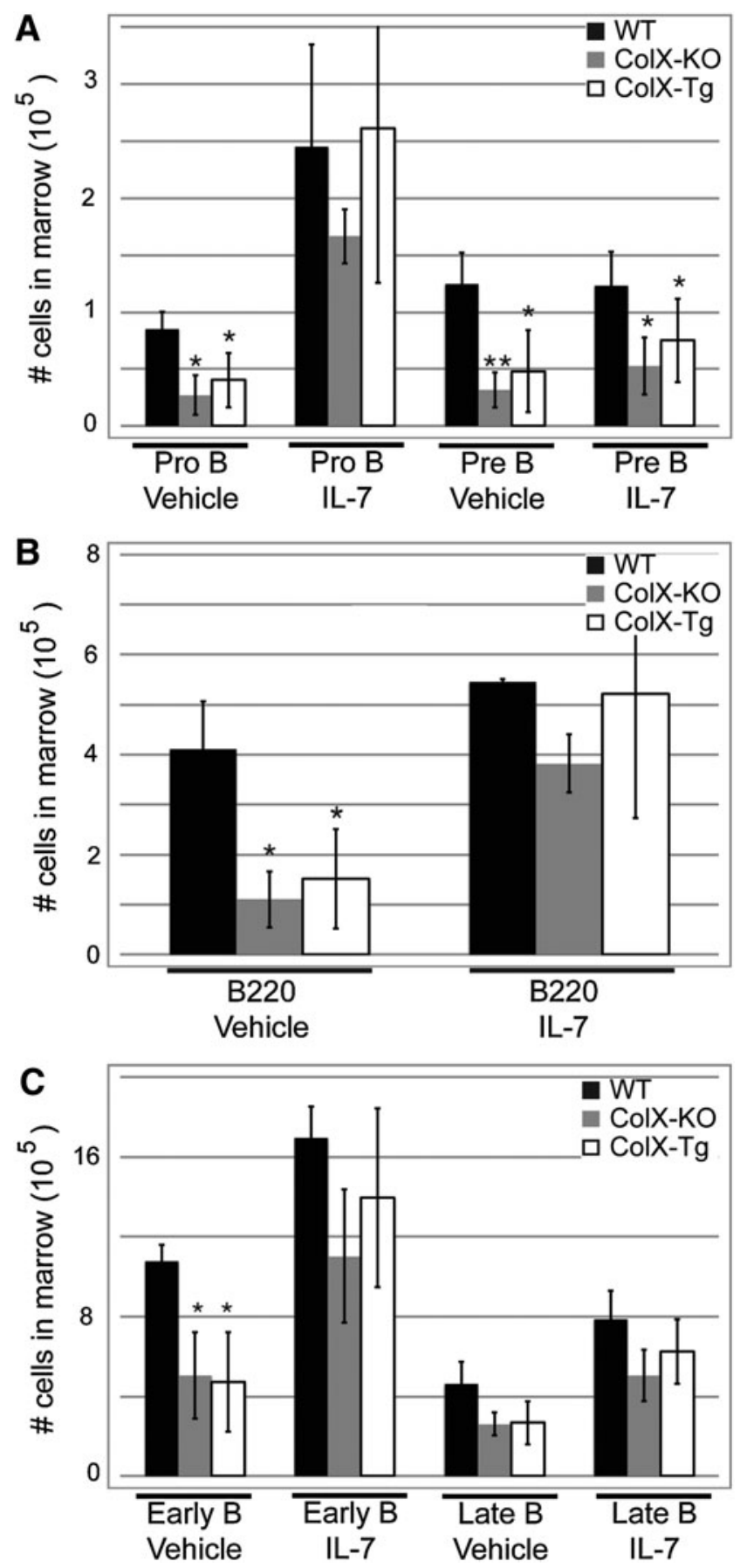

FIG. 6. In vivo IL-7 injections rescue B cell defect in collagen $X$ mice. (A) Quantitation of Pro-B, and Pre-B marrow cells from WT, collagen $X$ null and transgenic ( $\mathrm{KO}$ and $\mathrm{Tg}$ ) day 7 mice after 4 days of IL-7 injections. (B) Quantitation of total $\mathrm{B} 220+$ marrow cells in day 7 mice after IL-7 injections. (C) Early and late B marrow cells were quantified in day 21 mice after 4 days of IL-7 injections. ${ }^{*} P<0.05,{ }^{* *} P<0.001$. $n \geq 6$ mice per group.

A third finding of this study was the diminished B cell outgrowth in coculture assays using ColX-KO derived trabecular bone cells (Fig. 3A). These data were unexpected since the defect in the $\mathrm{ColX}-\mathrm{Tg} / \mathrm{KO}$ mice resides in the ability of the hypertrophic chondrocytes to generate a functional
ColX matrix network [36]. Therefore, we had predicted that a defect in B cell outgrowth would be observed with the hypertrophic chondrocyte feeder layers. However, these data highlight an integral relationship between trabecular bone cells and hypertrophic chondrocytes, and resurrect an unresolved cell lineage issue. While it is undisputed that trabecular bone forms as a hybrid tissue with a bone layer on top of a hypertrophic cartilage matrix core (Fig. 2) [67-79], the fate of hypertrophic chondrocytes undergoing EO is still uncertain [80]. Terminal hypertrophic chondrocytes have been documented to undergo apoptosis [81-85] and autophagy [86], but have also been proposed to mature to bone-like cells expressing osterix, collagen I, ALP, osteonectin, osteopontin, bone gla protein, and decreased collagen II and ColX $[72,73,79,87]$. Further, hypertrophic chondrocytes have been observed to undergo asymmetric cell divisions yielding osteoblast-like daughter cells at the COJ [77]. Yet, Maes et al. recently reported no contribution from the collagen II labeled hypertrophic chondrocytes to trabecular bone in a fate mapping mouse model [80]. While our data neither support nor rule out these possibilities, we also observed both hypertrophic cartilage and bone characteristics within the trabecular cultures (Fig. 2), even though the isolation protocols and culture conditions for trabecular osteoblasts and hypertrophic chondrocytes selected for one cell type over the other to minimize cell type contamination (Materials and Methods section).

Overall, it is conceivable that changes within hypertrophic cartilage may affect trabecular bone and hematopoietic niches either directly and/or indirectly. Indirect effects may include altered cross talk between hypertrophic chondrocytes and the local osteoblasts, osteocytes, and stromal cells either through cell-cell or cell-matrix communication. Due to the close proximity of the ColX matrix to the marrow space and its inclusion in trabecular spicules, it is possible that soluble signaling molecules bound to the hypertrophic cartilage matrix come in contact with trabecular osteoblasts and marrow cells, including hematopoietic and lymphopoietic progenitor cells. Thus, the COJ matrix could contribute to an indirect connection between the hypertrophic chondrocytes and cells of the marrow. In contrast, direct effects may include transdifferentiation of affected hypertrophic chondrocytes into impaired trabecular osteoblasts. These possibilities may not be mutually exclusive and have not been addressed by the current studies.

A fourth outcome of these studies highlights the reduced levels of hematopoietic cytokines at the COJ in the ColX-Tg/ $\mathrm{KO}$ mice both in vitro and in vivo (Fig. 4 and Table 2). This may represent the underlying cause of diminished B cell outgrowth in the cocultures, as well as reduced B cell numbers in vivo [39-41]. Indeed, adding exogenous cytokines to the ColX-KO trabecular cocultures rescued B lymphopoiesis (Fig. 5C), and injection of IL-7 in vivo rescued B cell numbers in the ColX-Tg/KO mice (Fig. 6). Additionally, our observation that both SCF and SDF-1 localize within the COJ (Fig. 4 ), in combination with the findings of Wei and colleagues that hypertrophic chondrocytes express the SDF-1 receptor CXCR4, again highlights the cross talk between the cells at the COJ $[21,33,88]$. Our coculture studies and cytokine analyses implicate the EO-derived trabecular bone cells in B lymphopoiesis, and concur with the current B lymphopoietic niche models. Although B cell niches are scattered throughout the marrow depending on the developmental stage of the 
B cell [31], they are reportedly made up of osteoblasts [21], reticular stromal cells [7-9,13,31,89], and IL-7 expressing stromal cells [90]. Further, it is noteworthy that the early B progenitor niche is comprised of SDF-1 producing cells $[31,89,91]$, and osteoblasts have been shown to secrete SDF-1, in addition to many other prohematopoietic cytokines $[13,21,33,42]$ (Table 2). Therefore, the COJ, comprised of cytokine secreting osteoblasts, hypertrophic chondrocytes, a unique COJ matrix, as well as the supportive stromal cells, may serve as a niche for early B cell development [42]. Moreover, perturbations to the niche, as observed in the $\mathrm{ColX}-\mathrm{Tg} / \mathrm{KO}$ mice due to changes in the hypertrophic chondrocyte matrix, lead to diminished B lymphopoiesis.

In conclusion, the data presented here add to our working hypothesis that the EO-derived COJ cells, along with associated ECM constituents, provide cytokine rich niches for hematopoiesis in the marrow. Moreover, these data suggest that not only are the EO-derived COJ cells constituents of the niche providing cell-cell, cell-ECM, and cytokine-ECM signals $[14,17,19,20,22,23,35,38-41,92]$, but that these cells are also a source of many hematopoietic cytokines (Table 2) [42]. Indeed, many of the hematopoietic cytokines tested, in particular IL-7, bind to HSPGs (Table 2), which in turn are known to create reservoirs of signaling molecules for local cells [93-95]. In accord, the altered COJ ECM in the ColX-Tg/ $\mathrm{KO}$ mice includes reduced ColX, HSPG and glycosaminoglycan (GAG) constituents [36], contributing to the disease phenotype of the ColX-Tg/KO mice. Additionally, although cytokines can be liberated from the ECM via matrix-specific enzymes [96,97], they may also be released from the ColX/ HSPG/GAG network within the trabecular core during bone remodeling by osteoclasts, again connecting the hypertrophic cartilage matrix to hematopoietic differentiation in the marrow. Thus, we envision that the ColX/HSPG/GAG network within the hypertrophic cartilage sequesters hematopoietic factors at the COJ for hematopoietic cell, as well as chondrocyte, osteoblast, stromal cell, signaling. In support, and in agreement with 'niche directed' disease mouse models, our recent bone marrow transplantations into $\mathrm{ColX}$ mice implicate a defective COJ environment, rather than cell autonomous alterations in hematopoietic precursor cells. Thus, we predict that our model, in which an altered niche environment leads to hematopoietic defects, may resemble human disorders, such as certain immuno-osseous disorders or myelodysplastic syndrome, and may guide future studies in identifying diseases resulting from altered niche components.

\section{Acknowledgments}

This publication was made possible by NIDDK grants DK088334 to OJ and NIAMS AR053804 NRSA and NIDDK DK085227 to ES.

\section{Author Disclosure Statement}

All authors state that they have no competing financial interests exist.

\section{References}

1. Aguila HL and DW Rowe. (2005). Skeletal development, bone remodeling, and hematopoiesis. Immunol Rev 208:7-18.
2. Caplan AI. (1990). Cartilage begets bone versus endochondral myelopoiesis. Clin Orthop Relat Res:257-267.

3. Cancro MP, Y Hao, JL Scholz, RL Riley, D Frasca, DK DunnWalters and BB Blomberg. (2009). B cells and aging: molecules and mechanisms. Trends Immunol 30:313-318.

4. Oh IH and KR Kwon. (2010). Concise review: multiple niches for hematopoietic stem cell regulations. Stem Cells 28:1243-1249.

5. Puron LE and DT Scadden. (2008). The hematopoietic stem cell niche. In: StemBook.org. Silberstein L ed. Harvard Stemcell Institute, Cambridge, MA, pp 1-14.

6. Ehninger A and A Trumpp. (2011). The bone marrow stem cell niche grows up: mesenchymal stem cells and macrophages move in. J Exp Med 208:421-428.

7. Hoggatt J and DT Scadden. (2012). The stem cell niche: tissue physiology at a single cell level. J Clin Invest 122:3029-3034.

8. Wang L, R Benedito, MG Bixel, D Zeuschner, M Stehling, L Savendahl, JJ Haigh, H Snippert, H Clevers, et al. (2013). Identification of a clonally expanding haematopoietic compartment in bone marrow. EMBO J 32:219-230.

9. Lo Celso C and DT Scadden. (2011). The haematopoietic stem cell niche at a glance. J Cell Sci 124:3529-3535.

10. Chan D and O Jacenko. (1998). Phenotypic and biochemical consequences of collagen $\mathrm{X}$ mutations in mice and humans. Matrix Biol 17:169-184.

11. Wu JY, DT Scadden and HM Kronenberg. (2009). Role of the osteoblast lineage in the bone marrow hematopoietic niches. J Bone Miner Res 24:759-764.

12. Adams GB, KT Chabner, IR Alley, DP Olson, ZM Szczepiorkowski, MC Poznansky, CH Kos, MR Pollak, EM Brown and DT Scadden. (2006). Stem cell engraftment at the endosteal niche is specified by the calcium-sensing receptor. Nature 439:599-603.

13. Balduino A, SP Hurtado, P Frazao, CM Takiya, LM Alves, LE Nasciutti, MC El-Cheikh and R Borojevic. (2005). Bone marrow subendosteal microenvironment harbours functionally distinct haemosupportive stromal cell populations. Cell Tissue Res 319:255-266.

14. Calvi LM, GB Adams, KW Weibrecht, JM Weber, DP Olson, MC Knight, RP Martin, E Schipani, P Divieti, et al. (2003). Osteoblastic cells regulate the haematopoietic stem cell niche. Nature 425:841-846.

15. de Barros AP, CM Takiya, LR Garzoni, ML Leal-Ferreira, HS Dutra, LB Chiarini, MN Meirelles, R Borojevic and MI Rossi. (2010). Osteoblasts and bone marrow mesenchymal stromal cells control hematopoietic stem cell migration and proliferation in 3D in vitro model. PLoS One 5:e9093.

16. Kieslinger M, S Hiechinger, G Dobreva, GG Consalez and R Grosschedl. (2010). Early B cell factor 2 regulates hematopoietic stem cell homeostasis in a cell-nonautonomous manner. Cell Stem Cell 7:496-507.

17. Raaijmakers MH, S Mukherjee, S Guo, S Zhang, T Kobayashi, JA Schoonmaker, BL Ebert, F Al-Shahrour, RP Hasserjian, et al. (2010). Bone progenitor dysfunction induces myelodysplasia and secondary leukaemia. Nature 464:852-857.

18. Taichman RS, MJ Reilly and SG Emerson. (1996). Human osteoblasts support human hematopoietic progenitor cells in vitro bone marrow cultures. Blood 87:518-524.

19. Visnjic D, Z Kalajzic, DW Rowe, V Katavic, J Lorenzo and HL Aguila. (2004). Hematopoiesis is severely altered in mice with an induced osteoblast deficiency. Blood 103:3258-3264.

20. Wu JY, LE Purton, SJ Rodda, M Chen, LS Weinstein, AP McMahon, DT Scadden and HM Kronenberg. (2008). Osteoblastic regulation of $\mathrm{B}$ lymphopoiesis is mediated by 
Gs\{alpha\}-dependent signaling pathways. Proc Natl Acad Sci U S A 105:16976-16981.

21. Zhu J, R Garrett, Y Jung, Y Zhang, N Kim, J Wang, GJ Joe, E Hexner, Y Choi, RS Taichman and SG Emerson. (2007). Osteoblasts support B-lymphocyte commitment and differentiation from hematopoietic stem cells. Blood 109:37063712.

22. Calvi LM, NA Sims, JL Hunzelman, MC Knight, A Giovannetti, JM Saxton, HM Kronenberg, R Baron and E Schipani. (2001). Activated parathyroid hormone/parathyroid hormone-related protein receptor in osteoblastic cells differentially affects cortical and trabecular bone. J Clin Invest 107:277-286.

23. Visnjic D, I Kalajzic, G Gronowicz, HL Aguila, SH Clark, AC Lichtler and DW Rowe. (2001). Conditional ablation of the osteoblast lineage in Col2.3deltatk transgenic mice. J Bone Miner Res 16:2222-2231.

24. Kiel MJ, OH Yilmaz, T Iwashita, OH Yilmaz, C Terhorst and SJ Morrison. (2005). SLAM family receptors distinguish hematopoietic stem and progenitor cells and reveal endothelial niches for stem cells. Cell 121:1109-1121.

25. Mendez-Ferrer S, TV Michurina, F Ferraro, AR Mazloom, BD Macarthur, SA Lira, DT Scadden, A Ma'ayan, GN Enikolopov and PS Frenette. (2010). Mesenchymal and haematopoietic stem cells form a unique bone marrow niche. Nature 466:829-834.

26. Sacchetti B, A Funari, S Michienzi, S Di Cesare, S Piersanti, I Saggio, E Tagliafico, S Ferrari, PG Robey, M Riminucci and P Bianco. (2007). Self-renewing osteoprogenitors in bone marrow sinusoids can organize a hematopoietic microenvironment. Cell 131:324-336.

27. Avecilla ST, K Hattori, B Heissig, R Tejada, F Liao, K Shido, DK Jin, S Dias, F Zhang, et al. (2004). Chemokine-mediated interaction of hematopoietic progenitors with the bone marrow vascular niche is required for thrombopoiesis. Nat Med 10:64-71.

28. Guba SC, CI Sartor, LR Gottschalk, YH Jing, T Mulligan and SG Emerson. (1992). Bone marrow stromal fibroblasts secrete interleukin- 6 and granulocyte-macrophage colonystimulating factor in the absence of inflammatory stimulation: demonstration by serum-free bioassay, enzyme-linked immunosorbent assay, and reverse transcriptase polymerase chain reaction. Blood 80:1190-1198.

29. Kopp HG, ST Avecilla, AT Hooper and S Rafii. (2005). The bone marrow vascular niche: home of HSC differentiation and mobilization. Physiology (Bethesda) 20: 349-356.

30. Osmond DG. (1990). B cell development in the bone marrow. Semin Immunol 2:173-180.

31. Tokoyoda K, T Egawa, T Sugiyama, BI Choi and T Nagasawa. (2004). Cellular niches controlling B lymphocyte behavior within bone marrow during development. Immunity 20:707-718.

32. Verfaillie CM. (1993). Soluble factor(s) produced by human bone marrow stroma increase cytokine-induced proliferation and maturation of primitive hematopoietic progenitors while preventing their terminal differentiation. Blood 82: 2045-2053.

33. Jung Y, J Wang, A Schneider, YX Sun, AJ Koh-Paige, NI Osman, LK McCauley and RS Taichman. (2006). Regulation of SDF-1 (CXCL12) production by osteoblasts; a possible mechanism for stem cell homing. Bone 38:497-508.

34. Mazzucchelli RI, S Warming, SM Lawrence, M Ishii, M Abshari, AV Washington, L Feigenbaum, AC Warner, DJ
Sims, et al. (2009). Visualization and identification of IL-7 producing cells in reporter mice. PLoS One 4:e7637.

35. Jacenko O, PA LuValle and BR Olsen. (1993). Spondylometaphyseal dysplasia in mice carrying a dominant negative mutation in a matrix protein specific for cartilage-to-bone transition. Nature 365:56-61.

36. Jacenko O, D Chan, A Franklin, S Ito, CB Underhill, JF Bateman and MR Campbell. (2001). A dominant interference collagen $X$ mutation disrupts hypertrophic chondrocyte pericellular matrix and glycosaminoglycan and proteoglycan distribution in transgenic mice. Am J Pathol 159:22572269.

37. Stacey A, J Bateman, T Choi, T Mascara, W Cole and R Jaenisch. (1988). Perinatal lethal osteogenesis imperfecta in transgenic mice bearing an engineered mutant pro-alpha 1(I) collagen gene. Nature 332:131-136.

38. Sweeney E, M Campbell, K Watkins, CA Hunter and O Jacenko. (2008). Altered endochondral ossification in collagen $X$ mouse models leads to impaired immune responses. Dev Dyn 237:2693-2704.

39. Sweeney E, D Roberts, T Corbo and O Jacenko. (2010). Congenic mice confirm that collagen $\mathrm{X}$ is required for proper hematopoietic development. PLoS One 5:e9518.

40. Jacenko O, DW Roberts, MR Campbell, PM McManus, CJ Gress and Z Tao. (2002). Linking hematopoiesis to endochondral skeletogenesis through analysis of mice transgenic for collagen X. Am J Pathol 160:2019-2034.

41. Gress CJ and O Jacenko. (2000). Growth plate compressions and altered hematopoiesis in collagen $\mathrm{X}$ null mice. J Cell Biol 149:983-993.

42. Sweeney E, D Roberts and O Jacenko. (2011). Altered matrix at the chondro-osseous junction leads to defects in lymphopoiesis. Ann N Y Acad Sci 1237:79-87.

43. Sweeney E and O Jacenko. (2012). Skeletogenesis and the hematopoietic niche. In: Advances in Hematopoietic Stem Cell Research. Pelayo R ed. InTech, Rijeka. pp 147-184.

44. Kwan KM, MK Pang, S Zhou, SK Cowan, RY Kong, T Pfordte, BR Olsen, DO Sillence, PP Tam and KS Cheah. (1997). Abnormal compartmentalization of cartilage matrix components in mice lacking collagen $\mathrm{X}$ : implications for function. J Cell Biol 136:459-471.

45. Rodgers KD, JD San Antonio and O Jacenko. (2008). Heparan sulfate proteoglycans: a GAGgle of skeletal-hematopoietic regulators. Dev Dyn 237:2622-2642.

46. Campbell MR, CJ Gress, EH Appleman and O Jacenko. (2004). Chicken collagen $X$ regulatory sequences restrict transgene expression to hypertrophic cartilage in mice. Am J Pathol 164:487-499.

47. Hildebrand T, A Laib, R Muller, J Dequeker and P Ruegsegger. (1999). Direct three-dimensional morphometric analysis of human cancellous bone: microstructural data from spine, femur, iliac crest, and calcaneus. J Bone Miner Res 14:1167-1174.

48. San Antonio JD, O Jacenko, M Yagami and RS Tuan. (1992). Polyionic regulation of cartilage development: promotion of chondrogenesis in vitro by polylysine is associated with altered glycosaminoglycan biosynthesis and distribution. Dev Biol 152:323-335.

49. Jung Y, J Wang, A Havens, Y Sun, J Wang, T Jin and RS Taichman. (2005). Cell-to-cell contact is critical for the survival of hematopoietic progenitor cells on osteoblasts. Cytokine 32:155-162.

50. Bock TA. (1997). Assay systems for hematopoietic stem and progenitor cells. Stem Cells 15 Suppl 1:185-195. 
51. Rosati R, GS Horan, GJ Pinero, S Garofalo, DR Keene, WA Horton, E Vuorio, B de Crombrugghe and RR Behringer. (1994). Normal long bone growth and development in type X collagen-null mice. Nat Genet 8:129-135.

52. Jacenko O and RS Tuan. (1986). Calcium deficiency induces expression of cartilage-like phenotype in chick embryonic calvaria. Dev Biol 115:215-232.

53. Ueda Y, M Kondo and G Kelsoe. (2005). Inflammation and the reciprocal production of granulocytes and lymphocytes in bone marrow. J Exp Med 201:1771-1780.

54. Weitzmann MN, C Roggia, G Toraldo, L Weitzmann and R Pacifici. (2002). Increased production of IL-7 uncouples bone formation from bone resorption during estrogen deficiency. J Clin Invest 110:1643-1650.

55. McNiece IK, KE Langley and KM Zsebo. (1991). The role of recombinant stem cell factor in early B cell development. Synergistic interaction with IL-7. J Immunol 146:3785-3790.

56. Nagasawa T, H Kikutani and T Kishimoto. (1994). Molecular cloning and structure of a pre-B-cell growth-stimulating factor. Proc Natl Acad Sci U S A 91:2305-2309.

57. Morrissey PJ, P Conlon, K Charrier, S Braddy, A Alpert, D Williams, AE Namen and D Mochizuki. (1991). Administration of IL-7 to normal mice stimulates B-lymphopoiesis and peripheral lymphadenopathy. J Immunol 147:561-568.

58. Faltynek CR, S Wang, D Miller, E Young, L Tiberio, K Kross, M Kelley and E Kloszewski. (1992). Administration of human recombinant IL-7 to normal and irradiated mice increases the numbers of lymphocytes and some immature cells of the myeloid lineage. J Immunol 149:1276-1282.

59. Kuznetsov SA, M Riminucci, N Ziran, TW Tsutsui, A Corsi, L Calvi, HM Kronenberg, E Schipani, PG Robey and P Bianco. (2004). The interplay of osteogenesis and hematopoiesis: expression of a constitutively active PTH/PTHrP receptor in osteogenic cells perturbs the establishment of hematopoiesis in bone and of skeletal stem cells in the bone marrow. J Cell Biol 167:1113-1122.

60. Aguila HL, SH Mun, J Kalinowski, DJ Adams, JA Lorenzo and SK Lee. (2012). Osteoblast-specific overexpression of human interleukin-7 rescues the bone mass phenotype of interleukin-7-deficient female mice. J Bone Miner Res 27: 1030-1042.

61. Pacifici R. (2010). The immune system and bone. Arch Biochem Biophys 503:41-53.

62. Li Y, G Toraldo, A Li, X Yang, H Zhang, WP Qian and MN Weitzmann. (2007). B cells and T cells are critical for the preservation of bone homeostasis and attainment of peak bone mass in vivo. Blood 109:3839-3848.

63. Nah HD, M Pacifici, LC Gerstenfeld, SL Adams and T Kirsch. (2000). Transient chondrogenic phase in the intramembranous pathway during normal skeletal development. J Bone Miner Res 15:522-533.

64. Jacenko O, JD San Antonio and RS Tuan. (1995). Chondrogenic potential of chick embryonic calvaria: II. Matrix calcium may repress cartilage differentiation. Dev Dyn 202: $27-41$.

65. Jacenko O and RS Tuan. (1995). Chondrogenic potential of chick embryonic calvaria: I. Low calcium permits cartilage differentiation. Dev Dyn 202:13-26.

66. Eames BF, L de la Fuente and JA Helms. (2003). Molecular ontogeny of the skeleton. Birth Defects Res C Embryo Today 69:93-101.

67. Holtrop ME. (1972). The ultrastructure of the epiphyseal plate. II. The hypertrophic chondrocyte. Calcif Tissue Res 9: 140-151.
68. Crelin ES and WE Koch. (1967). An autoradiographic study of chondrocyte transformation into chondroclasts and osteocytes during bone formation in vitro. Anat Rec 158:473-483.

69. Shimomura Y, T Yoneda and F Suzuki. (1975). Osteogenesis by chondrocytes from growth cartilage of rat rib. Calcif Tissue Res 19:179-187.

70. Yoshioka C and T Yagi. (1988). Electron microscopic observations on the fate of hypertrophic chondrocytes in condylar cartilage of rat mandible. J Craniofac Genet Dev Biol 8: 253-264.

71. Moskalewski S and J Malejczyk. (1989). Bone formation following intrarenal transplantation of isolated murine chondrocytes: chondrocyte-bone cell transdifferentiation? Development 107:473-480.

72. Galotto M, G Campanile, G Robino, FD Cancedda, P Bianco and R Cancedda. (1994). Hypertrophic chondrocytes undergo further differentiation to osteoblast-like cells and participate in the initial bone formation in developing chick embryo. J Bone Miner Res 9:1239-1249.

73. Strauss PG, EI Closs, J Schmidt and V Erfle. (1990). Gene expression during osteogenic differentiation in mandibular condyles in vitro. J Cell Biol 110:1369-1378.

74. Closs EI, AB Murray, J Schmidt, A Schon, V Erfle and PG Strauss. (1990). c-fos expression precedes osteogenic differentiation of cartilage cells in vitro. J Cell Biol 111: 1313-1323.

75. von der Mark K and H von der Mark. (1977). The role of three genetically distinct collagen types in endochondral ossification and calcification of cartilage. J Bone Joint Surg Br 59-B:458-464.

76. Roach HI. (1992). Trans-differentiation of hypertrophic chondrocytes into cells capable of producing a mineralized bone matrix. Bone Miner 19:1-20.

77. Roach HI and J Erenpreisa. (1996). The phenotypic switch from chondrocytes to bone-forming cells involves asymmetric cell division and apoptosis. Connect Tissue Res 35:85-91.

78. Roach HI, J Erenpreisa and T Aigner. (1995). Osteogenic differentiation of hypertrophic chondrocytes involves asymmetric cell divisions and apoptosis. J Cell Biol 131: 483-494.

79. Descalzi Cancedda F, C Gentili, P Manduca and R Cancedda. (1992). Hypertrophic chondrocytes undergo further differentiation in culture. J Cell Biol 117:427-435.

80. Maes C, T Kobayashi, MK Selig, S Torrekens, SI Roth, S Mackem, G Carmeliet and HM Kronenberg. (2010). Osteoblast precursors, but not mature osteoblasts, move into developing and fractured bones along with invading blood vessels. Dev Cell 19:329-344.

81. Farnum CE, J Turgai and NJ Wilsman. (1990). Visualization of living terminal hypertrophic chondrocytes of growth plate cartilage in situ by differential interference contrast microscopy and time-lapse cinematography. J Orthop Res 8:750-763.

82. Farnum CE and NJ Wilsman. (1989). Cellular turnover at the chondro-osseous junction of growth plate cartilage: analysis by serial sections at the light microscopical level. J Orthop Res 7:654-666.

83. Hunziker EB, W Herrmann, RK Schenk, M Mueller and H Moor. (1984). Cartilage ultrastructure after high pressure freezing, freeze substitution, and low temperature embedding. I. Chondrocyte ultrastructure-implications for the theories of mineralization and vascular invasion. J Cell Biol 98:267-276. 
84. Anderson CE and J Parker. (1966). Invasion and resorption in enchondral ossification. An electron microscopic study. J Bone Joint Surg Am 48:899-914.

85. Brighton CT, Y Sugioka and RM Hunt. (1973). Cytoplasmic structures of epiphyseal plate chondrocytes. Quantitative evaluation using electron micrographs of rat costochondral junctions with special reference to the fate of hypertrophic cells. J Bone Joint Surg Am 55:771-784.

86. Srinivas V and IM Shapiro. (2006). Chondrocytes embedded in the epiphyseal growth plates of long bones undergo autophagy prior to the induction of osteogenesis. Autophagy 2:215-216.

87. Yagi K, K Tsuji, A Nifuji, K Shinomiya, K Nakashima, B DeCrombrugghe and M Noda. (2003). Bone morphogenetic protein-2 enhances osterix gene expression in chondrocytes. J Cell Biochem 88:1077-1083.

88. Wei L, K Kanbe, M Lee, X Wei, M Pei, X Sun, R Terek and Q Chen. (2010). Stimulation of chondrocyte hypertrophy by chemokine stromal cell-derived factor 1 in the chondroosseous junction during endochondral bone formation. Dev Biol 341:236-245.

89. Sugiyama T, H Kohara, M Noda and T Nagasawa. (2006). Maintenance of the hematopoietic stem cell pool by CXCL12-CXCR4 chemokine signaling in bone marrow stromal cell niches. Immunity 25:977-988.

90. Funk PE, RP Stephan and PL Witte. (1995). Vascular cell adhesion molecule 1-positive reticular cells express interleukin-7 and stem cell factor in the bone marrow. Blood 86:2661-2671.

91. Nagasawa T. (2006). Microenvironmental niches in the bone marrow required for B-cell development. Nat Rev Immunol 6:107-116

92. Zhang J, C Niu, L Ye, H Huang, X He, WG Tong, J Ross, J Haug, T Johnson, et al. (2003). Identification of the haematopoietic stem cell niche and control of the niche size. Nature 425:836-841.

93. Verfaillie CM, P Gupta, F Prosper, R Hurley, B Lundell and R Bhatia. (1999). The hematopoietic microenvironment: stromal extracellular matrix components as growth regulators for human hematopoietic progenitors. Hematology 4:321-333.

94. Borghesi LA, Y Yamashita and PW Kincade. (1999). Heparan sulfate proteoglycans mediate interleukin-7-dependent $B$ lymphopoiesis. Blood 93:140-148.

95. Gupta P, TR Oegema, Jr., JJ Brazil, AZ Dudek, A Slungaard and CM Verfaillie. (1998). Structurally specific heparan sulfates support primitive human hematopoiesis by formation of a multimolecular stem cell niche. Blood 92:46414651.

96. Heissig B, K Hattori, S Dias, M Friedrich, B Ferris, NR Hackett, RG Crystal, P Besmer, D Lyden, et al. (2002). Recruitment of stem and progenitor cells from the bone marrow niche requires MMP-9 mediated release of kit-ligand. Cell 109:625-637.

97. Spiegel A, E Zcharia, Y Vagima, T Itkin, A Kalinkovich, A Dar, O Kollet, N Netzer, K Golan, et al. (2008). Heparanase regulates retention and proliferation of primitive Sca-1+ /c$\mathrm{Kit}+$ /Lin- cells via modulation of the bone marrow microenvironment. Blood 111:4934-4943.

Address correspondence to: Dr. Olena Jacenko

Division of Biochemistry

Department of Animal Biology

School of Veterinary Medicine

University of Pennsylvania

3800 Spruce Street, Rosenthal Rm 152

Philadelphia, PA 19104-6046

E-mail: jacenko@vet.upenn.edu

Received for publication July 16, 2012

Accepted after revision May 7, 2013

Prepublished on Liebert Instant Online May 8, 2013 